\title{
Article \\ Study on Riparian Shading Envelope for Wetlands to Create Desirable Urban Bioclimates
}

\author{
Abu Taib Mohammed Shahjahan ${ }^{1, * \mathbb{C}}$, Khandaker Shabbir Ahmed ${ }^{2}\left(\mathbb{D}\right.$ and Ismail Bin Said ${ }^{3}$ \\ 1 Department of Architecture, American International University-Bangladesh (AIUB), 408/1 (new), Kuril, \\ Kuratoli Road, Dhaka 1229, Bangladesh \\ 2 Department of Architecture, Bangladesh University of Engineering and Technology, \\ Dhaka 1000, Bangladesh; shabbir@arch.buet.ac.bd \\ 3 Department of Landscape Architecture, Faculty of Built Environment and Surveying, \\ Universiti Teknologi Malaysia, Skudai 81310, Johor, Malaysia; b-ismail@utm.my \\ * Correspondence: ashahjahan@aiub.edu; Tel.: +88-01730-436953
}

Received: 19 October 2020; Accepted: 7 December 2020; Published: 12 December 2020

\begin{abstract}
Climate change and rapid urbanization are adversely affecting the urban environment by exacerbating the widely reported urban heat island effect in Dhaka, Bangladesh. Two wetland areas with variable riparian shadings in the warm-humid conditions of urban Dhaka were investigated through field campaigns on microclimatic parameters for their cooling potential on the surrounding urban fabric. It was observed that an inversion layer of fully saturated air develops over the water surface of wetland, suppressing evaporation from the wetland water surface layer, which was effectively reducing the heat exchange between the water surface and the air layer above it through its action as an insulating vapor blanket. Due to this effect, the wetland was unable to render as a source of coolth for the surrounding overheated urban area. This effect of the inversion layer was more pronounced in the urban wetland without riparian shading either by the urban form or tree canopy. A multiphysics simulation study conducted on the selected urban wetlands indicates the effect of differential shading pattern on the relation between fetch and inversion layer thickness. This research hypothesizes that the wetland can act as an urban adaption measure against the urban heat island effect by potentially transforming them into an urban cooling island (UCI) towards a favorable urban bioclimate.
\end{abstract}

Keywords: urban bioclimate; urban cooling; urban wetland; riparian shading; inversion layer

\section{Introduction}

Urbanization in the developing world is dramatic if compared with the standard of today's urbanized world. Within a short period, the urban population in the developing world superseded the developed world. However, most of the rural-urban migration in the developing world is for economic reasons, as the city offers better opportunities in terms of livelihood. Still, in recent times, most of the rural-urban migrations in the developing world are related to global climate change. Much of the urban areas of the developing world are in the tropical zone, where urbanization is distinctive from a climate, demography, and cultural point of view. According to the IPCC (Intergovernmental Panel on Climate Change), Bangladesh is the sixth most vulnerable country to climate change [1]. At present, Dhaka is the densest and one of the most populated cities in the whole world; in 2016, its population was more than 14 million [2,3]. Wetlands and green spaces are diminishing due to unprecedented and often unplanned urbanization, in addition to pressure from the housing sector. Within 20 years (1989-2009), urban wetlands in Dhaka metropolitan area have been reduced from $26.68 \%$ of the total city area to $9.27 \%$, which is approximately a $65 \%$ reduction [4]. One of the climate-related extreme that 
we are facing in Dhaka, like other megacities in the world, is the urban heat island (UHI), which is exacerbated by growing global temperatures. From numerous studies on UHI mitigation, it can concur that urban water bodies can play an active role in mitigating UHI through microclimatic cooling of the urban area by creating cool spots. As these cool spots can transport coolth inside the urban fabric, they can be termed as urban cooling islands (UCIs). Besides the wetland, urban parks can also act as UCIs for their evapotranspiration effect and shading of the trees. However, as the heat content capacity of the water is high, it could counteract the UCIs effect if kept unshaded. Urban wetland shaded by buildings, topography, and shade trees can have a proficient effect on microclimatic cooling. In contrast, riparian shade can have a positive effect on the UCIs and on the water quality. The result of riparian shade on the water body is mostly observed on the linear and narrow streams having a less urban build up on either side [5]. There are few studies about the effect of riparian shade in the broader water body. Additionally, most of the studies [5-7] suggest a small area and regular (Euclidean shape) shape water body distributed at regular intervals in an urban area makes for better urban cooling island (UCI) intensity. Hence, the primary research question is, how can the introduction of riparian shade moderate the negative impact of the heat capacity of the reservoirs on UCIs?

Wetlands of urban areas can have a profound impact on the urban canopy layer (UCL) climate levels. Wetlands lower temperature increases, relative humidity, and also lower heat stress index at the downwind side, which is also known as the "Lake Effect" [8]. "Wetlands include reservoirs, lakes, and rivers, and form many Urban Cooling Islands (UCIs)" [5]. Most of the UHI studies are implemented at the scale of an entire city. For this reason, there is little information available on the effect of individual wetlands. Various details on the particular wetland, such as the difference of temperature between the wetland and its surrounding landscapes and the transport of cooling effects of wetlands in different spatial scales, are not known. Several works investigated the existence of UCI, the factors having an impact on the UCI intensity and the extent of UCI [7,9-24]. Fraedrich (1972) [25] investigated the existence of the "inversion layer" when the air is blowing from the warmer land over the surface of the waterbody. Inversion increasingly suppresses the evaporation, increasing with the distance traveled over the reservoir by creating a "vapor blanket". Steeneveld et al., 2014, [6] suggest that "water bodies might not act as cooling elements in an urban area, especially during the night and evenings in the late summer, due to the extensive heat capacity of water bodies compared to their milieu. The shade of Riparian vegetation could counter the negative effect of warming of the stream water and helps ecosystems to adapt [19]. The positive impact of Riparian shade to moderate air and water temperature also investigated various research work [19,20,26-30]. Rosenberg et al., 1983 [31], reported several examples of leading-edge effects at Davis, CA, near Sacramento due to evaporation produced by irrigated fields surrounded by semiarid areas. Where a step-change in moisture availability had been observed [32-35]. Other significant works on the leading edge or fetch were conducted by Rider et al., 1963 [35], and Rijks 1971 [36]. Oke (1979) [37] also reported increased evaporation due to microscale advection in urban areas from the study of an irrigated suburban lawn in Vancouver, BC, USA.

One of the primary objectives of the creation of "Urban Cooling Island" is to create coolth and transport it inside the urban fabric to achieve a thermally desirable environment in the urban spaces. Through field investigation, Ahmed (1995) [38] established the comfort criteria for the outdoor urban areas of warm-humid cities like Dhaka. One of the requirements for outdoor comfort in the urban spaces of Dhaka were summarized from his work is that "Under still air conditions at an average relative humidity of $70 \%$, for people wearing summer clothing and engaged in sedentary activities or a stationary state, the range of comfort air temperature is between $28.5^{\circ} \mathrm{C}$ to $32^{\circ} \mathrm{C}^{\prime \prime}$. The critical parameter that influences the creation of the urban cooling island (UCI) is the shading provided to the water of wetland utilizing riparian vegetation and topography of the site. In case urban area, the urban fabric could also be designed in such a way that could act as a shading envelope for the urban wetlands. Additionally, the percentage of the built area around the water body, area, shape complexity, and water quality of the water body directly affects the creation of the urban cooling island 
(UCI). Among them, UCI has a two-way relationship with the water quality of the wetland. Based on the literature survey, we prepared the following Figure 1 to demonstrate the relation of the different environmental parameters related to the creation of UCI.

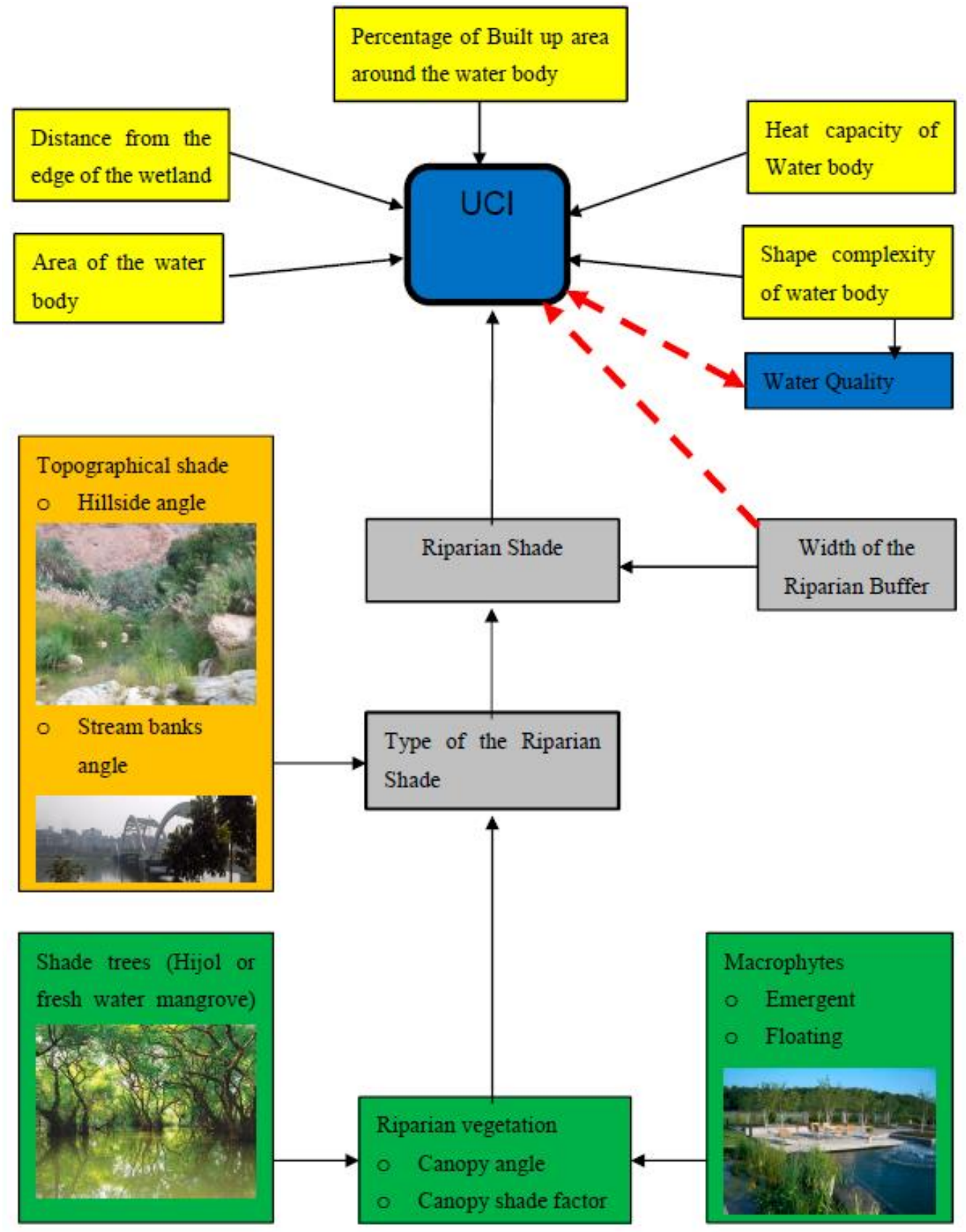

Figure 1. Relation of the different parameters related to the creation of UCI.

Hence, the specific aims of this research were to develop a sustainable path to transform potential wetlands of Dhaka into "Urban Cooling Islands (UCIs)" to address warming issues of Climate Change, which will also promote waterfront ecology with leisure and park amenities as they relate to the urban environment. There is a growing energy crisis in the city due to the high cooling energy demand. Therefore, urban cooling will be an effective way forward as an adaptation measure against climate change. This multidisciplinary research also aims to form an area of coexistence between natural and human-made structures in Dhaka. 


\section{Objectives of the Research}

i. To investigate the factors of urban wetland that contribute to urban cooling islands (UCIs) in Dhaka.

ii. To evaluate the impacts of wetland area, shape complexity, location, and riparian shading potential on UCIs intensity in Dhaka.

The novelty of the research is that it can potentially indicate the parametric relationship between the factors that regulate the urban cooling island (UCI) effect of the wetland at an urban scale. This relationship will give insight to what extent urban wetland design might impact the thermal environment leading to possible urban microclimatic cooling. These findings, in turn, might help in the development of a tool for the urban designers and planners to more efficiently manage the urban thermal environment. Although Fraedrich (1972) [25] investigated the existence of the "inversion layer" over water body, he did not explore its relationship with riparian shading of the wetland.

\section{Methodology}

This research followed the strategy of field study to support simulation and modeling research.

\subsection{Field Measurement of the Urban Cooling Island}

The main objective of the field measurement was to determine the morphological characteristics of the urban cooling island (UCI) at the urban canopy layer (UCL). For this reason, the measurement had been carried out in the two study areas at the urban canopy layer (UCL) at the height of 1.5-2 m from the ground. Some measurements were taken on top of the water surface and water edge to determine the effect of water on the air layer above it.

\subsubsection{Location of the Study Area and Urban Station}

Based on the previous study conducted by the Bangladesh Meteorological Department and Shahjahan et al., 2016 [39], two wetlands of urban Dhaka were selected for the field study. They were Dhanmondi and Hatirjheel Lake.

The rationale for selecting wetland sites are given below:

a. These two wetlands are accessible up to their inner periphery without any hindrance.

b. Both the wetlands have radiating roads leading into the surrounding urban fabric having the potentials for studying the impact of wetlands on the surrounding area.

c. To enable the analysis of the effect of riparian shade, Dhanmondi Lake was selected for its significantly visible riparian shade, and Hatirjheel Lake was chosen for the absence of visible riparian shade.

d. The watershed characteristics of both the lakes are comparable in terms of area.

e. Both the lakes are located on the same physiographic condition [40]; details are given in Appendix A). Agroecological zone for both the lakes are also the same [41].

f. Both the lakes are located in the same overall geothermal gradient zone [42].

The urban data logging station inside the urban area around these two wetlands were selected with the intent to detect the most significant impact of those wetlands on the microclimate of the encompassing urban fabric. Surrounding areas are uniform or more representative, at least within a half kilometer buffer zone. As per the urban climate zone (UCZ) classification by [43], the surrounding urban area of the selected urban wetland belongs to UCZ 2. These two existing urban wetlands in Dhaka were studied to discern the relationships among the factors such as UCI intensity and extent, wetland area, shape, location and heat capacity, and Riparian buffer width and type for the Riparian shade of the wetland. A buffer zone of $0.5 \mathrm{~km}$ from the edge of the wetlands (Figure 2) was taken into consideration for the field measurement. Within the buffer zone, multiple points starting from the 
water edge to the depth of the urban fabric were selected for microclimatic measurement in line with other studies performed in this field $[5,18,44]$.

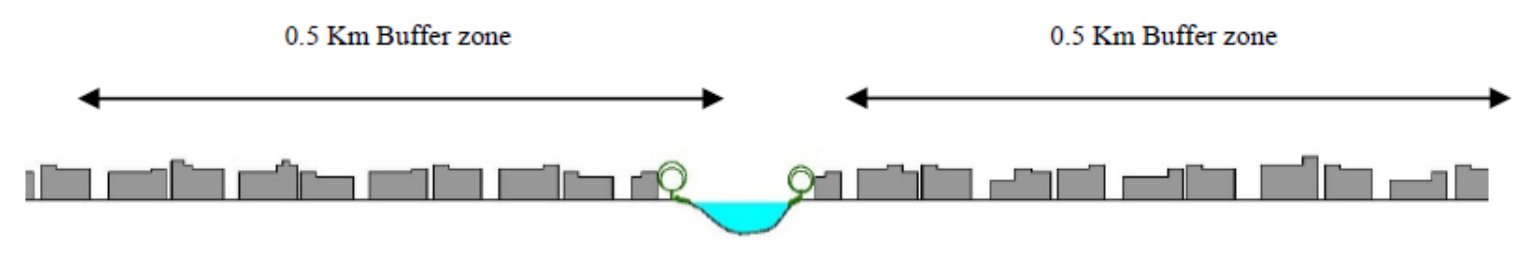

Figure 2. Buffer zone for field measurement.

\subsubsection{Date and Time of Data Logging}

Dates for the field measurement were selected from three design seasons of Dhaka, which are hot dry (March-May), warm humid (June-November), and cold dry (December-February). For all the measurements, the sky was mostly free of the cloud with bright sunlight. Data logging was done from morning to sunset on the following dates: at the Dhanmondi Lake site on 21 October 2016, 27 January 2017, and 24 February 2017 and at the Hatirjheel lakeside on 11 November 2016 and 10 February 2017. One additional data logging was done on 13 December 2016, at the Hatirjheel lake site. On this date, one data logger was simultaneously placed inside Stevenson Screen at the measurement point of the Bangladesh Meteorological Department (BMD) at Agargaon together with instruments of BMD from 11 a.m. on 12 December 2016 to 11 a.m. on 14 December 2016, for calibration of the device used in the study, and also as a reference measurement.

\subsubsection{Observation Period}

To investigate "urban microclimate" dynamics and the "urban heat island", selected observation days were chosen to typify a range of different weather statuses, like the three design seasons in Dhaka, other than rainy days. It was essential to attaining data of high geographical and temporal resolution. However, taking account of our limited budget and human resources, we were only able to collect 12-h samples of data on six occasions, starting from October to February, which was adequate for the research. The variables measured were air temperatures, humidity, and wind speed at $1.5-2.0 \mathrm{~m}$ height in the middle of the urban canopy layer and wetland edge from 7:00 a.m. of one day until 6:00 p.m. of the same day, except in one case where the data logger was placed with the Bangladesh Meteorological Department (BMD) instruments for three days for validation purpose. Wind direction and velocity, in our case, were measured just at the edge of the wetland. [44]. Detail information of each urban station of both the site on each measurement day is provided in Appendix A. Description of the instruments used in the measurement is also given in Appendix A.

\subsubsection{Climatic Variables Measured}

Air temperature (Ta), relative humidity (RH), and wind speed (ws) inside and around the selected urban wetlands had been measured at selected urban stations (data logging points) by continuous data logging using a fixed data logger.

\subsection{Simulation and Modeling}

Numerical models quantifying shading by riparian vegetation, topography, and built-form were built. The model was used to estimate the influence of wetlands in the microclimate of the surrounding area in real situations. The main objective of the simulation work was to determine the morphological characteristics of the urban cooling island (UCI) at the urban canopy layer (UCL). The principal assumption that has been tested in the simulation model is that the water in the wetland will be cooled down with the help of continuous riparian shading to act as UCI; this cooling effect will then be transferred to the urban fabric through the advective process. For this reason, the simulation work was conducted in one of the study areas described in the previous section at the urban canopy layer (UCL), 
recording the result at the height of 1.5-2 $\mathrm{m}$ from the ground. Some measurements were also recorded on top of the water surface and edge of the lake to determine the effect of water on the air layer above it. Data obtained from the field study of the two wetlands were entered into the COMSOL-Multiphysics software (COMSOL Inc., Stockholm, Sweden) as a part of the problem modeling study. Water and air temperature, relative humidity, and wind speed are primary inputs for the simulation besides types of ground cover and the built form. Once the problem modeling is done, the model was projected to test the specific effect of each contributing factor of the urban cooling island (UCI) described above. The principal assumption that had been tested in the simulation model was that the water in the wetland would be cooled down with the help of continuous shading and evaporation to act as UCI, which in turn will cool down the air above it and create the high-pressure zone. This cool air will then flow towards the nearest urban center with a low-pressure area owing to the UHI.

The modules of the COMSOL-Multiphysics that were combined with modeling the urban cooling island effect of the urban wetland is:

i. Computational Fluid Dynamics (CFD) module: fluid flow-single phase flow.

ii. Heat transfer module: heat transfer in fluids and heat transfer with surface to surface radiation (ht).

iii. Chemical species transport: transport of diluted species (tds).

\subsubsection{Location and Morphology of the Modeling Area}

An area (approximately $750 \mathrm{~m}$ length) adjacent to the Dhanmondi Lake, bounded by road 12A on the north-west, Satmasjid road on the south-west, and road 6A on the south-east side was selected for the simulation study as all the data loggers, with one exception, were placed in this zone to collect microclimatic data. Due to the limited computational strength of the computer available for the simulation study, this area was scaled down to a ratio of 1:50. Data obtained from the field measurement of these wetlands were entered into the COMSOL-Multiphysics software as an initial condition of the problem modeling study. Water and air temperature, relative humidity, and wind speed are primary inputs for the simulation besides types of ground cover and the built form. Although all the buildings in each block are the detached type, the gaps between the buildings in most of the cases are not more than $2 \mathrm{~m}$. So, for the sake of simplicity of the model, all the buildings in a single block were safely considered as a single building mass. The average building height of the area is approximately $24 \mathrm{~m}$. Additionally, only the part of the lake in the line of prevailing wind direction was modeled. One of the days of field measurement in this area, 24 February 2017, was used for the position of the sun in the simulation model. The simulation time was fixed from 9 a.m. to 4 p.m. on that day. The whole simulation study was conducted for four cases depicting four types of ambient conditions:

i. $\quad$ Case 1: The first simulation study was done with the water of the lake entirely under solar radiation and inlet temperature equal to the maximum temperature of the day obtained from the field measurement.

ii. Case 2: The second simulation study was conducted with the water of the lake entirely under solar radiation and inlet temperature equal to the minimum temperature of the day obtained from the field measurement.

iii. Case 3: The third simulation study was conducted with the water body completely shaded from solar radiation and inlet temperature equal to the maximum temperature of the day obtained from the field measurement.

iv. Case 4: The fourth simulation study was conducted with the water body completely shaded from solar radiation and inlet temperature equal to the minimum temperature of the day obtained from the field measurement.

In all four cases, relative humidity (RH), which is equal to starting $\mathrm{RH}$ at 9:00 a.m., was obtained from the field measurement on 24 February 2017. 


\subsubsection{Computational Grid (Mesh)}

In the COMSOL model, extremely fine mesh settings were used for the simulation model. The five parameters used to set up the mesh in COMSOL were the maximum element size $0.9 \mathrm{~m}$, minimum element size $0.009 \mathrm{~m}$, maximum element growth rate 1.3, curvature factor 0.2 , and resolution of narrow regions 1.5. A computational grid of the simulation domain is given in Figure 3.

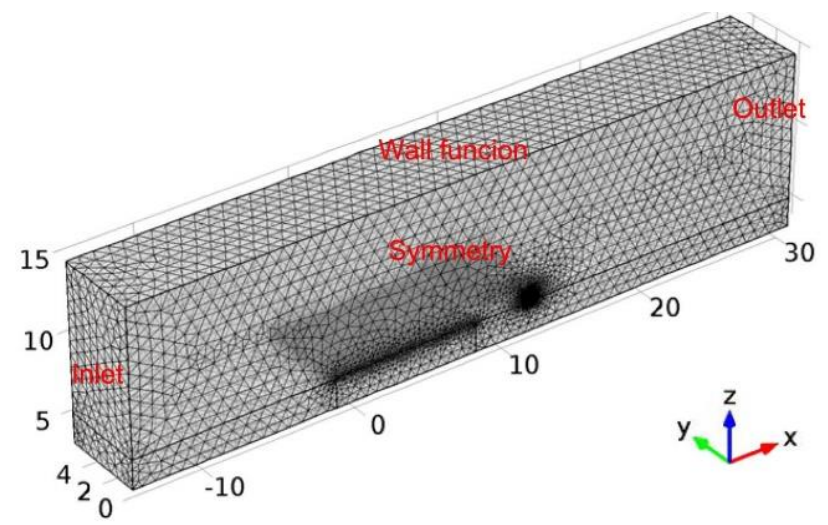

Figure 3. Computational grid of simulation domain (grid unit is meter).

From Figure 4, a computational grid of the model with its different areas can be seen.

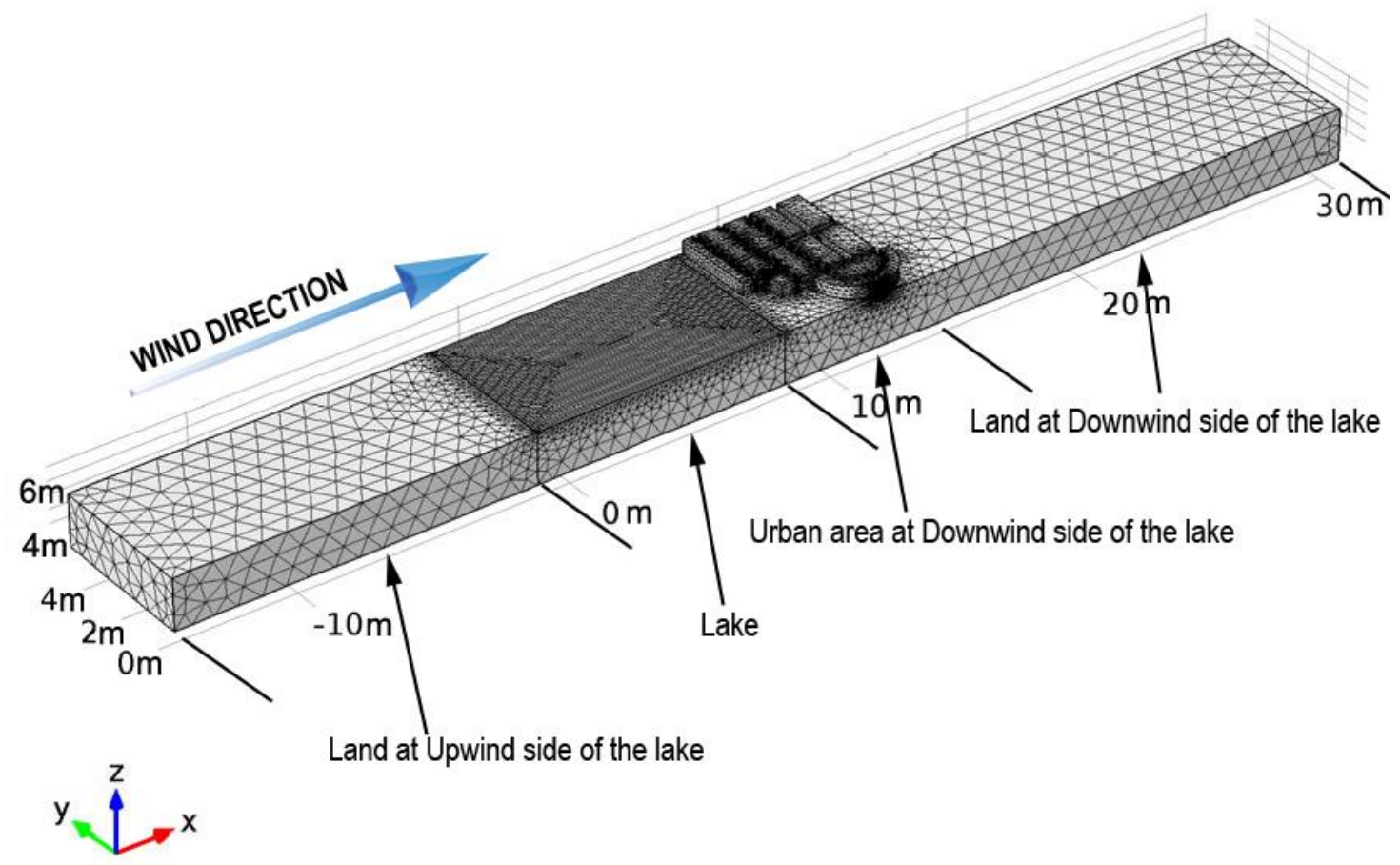

Figure 4. Computational grid of the model (grid unit is meter).

\subsubsection{Boundary Conditions}

Inlet Boundary Condition

Air enters the computational domain at a freestream velocity $U_{0}=0.2 \mathrm{~m} / \mathrm{s}$ normal to the inlet surface. 
Outlet Boundary Condition

At the outlet, a pressure condition is applied.

\section{Wall Condition}

Wall functions describe the floor of the flow domain and surface of the buildings. Wall functions could also be applied to the outer wall and the ceiling of the computational domain. Their main effect on the flow around the body is, however, to keep the flow contained, and it will, therefore, suffice to model them as slip walls.

\section{Symmetry Condition}

Mirror symmetry reduces the computational domain, as shown in Figure 5.

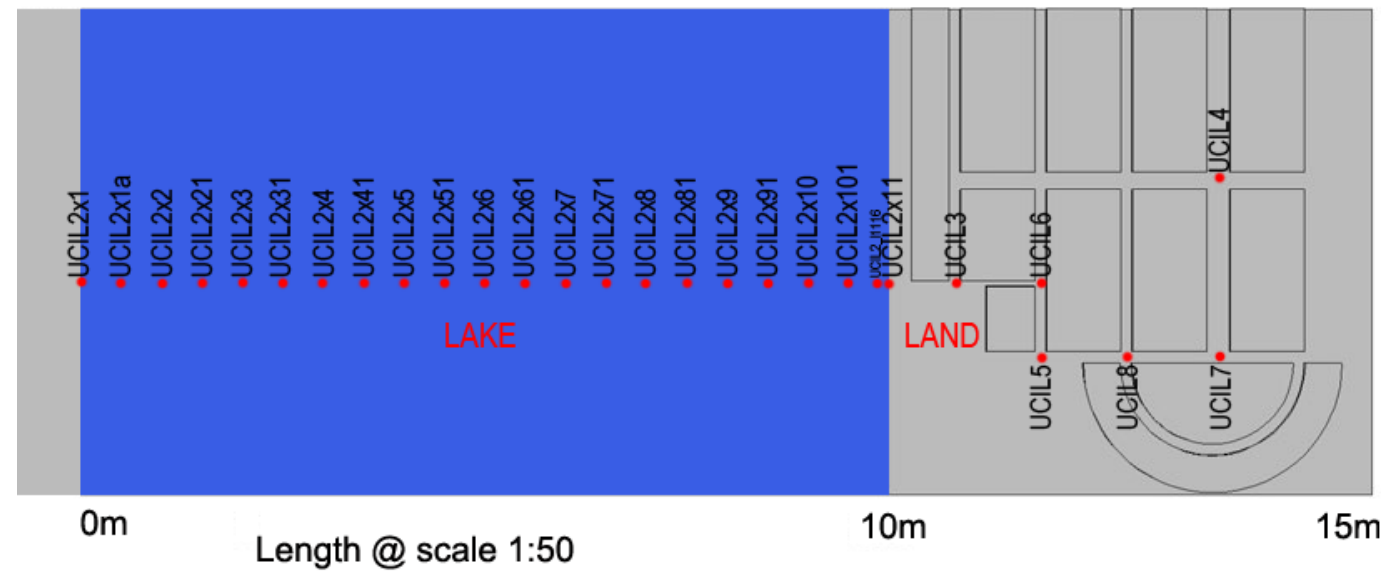

Figure 5. Measurement points of the model.

Temperature

There are three ambient temperature conditions in this model. First, for case 1, inlet temperature equal to the minimum temperature of the day obtained from the field measurement. Second, for case 2, inlet temperature corresponding to the maximum temperature of the day received from the field measurement. Third, the ground at $1 \mathrm{~m}$ below the sand surface was assumed to be at a constant temperature, corresponding to the minimum water temperature at this location for the measurement time of the day, which was from 9 a.m. to 4:00 p.m.

The modules of the COMSOL-Multiphysics that were combined with modeling the urban cooling island effect of the urban wetland were (1) CFD module: fluid flow-single phase flow, turbulent flow, $\mathrm{k}-\omega$; (2) heat transfer module: heat transfer in fluids and heat transfer with surface to surface radiation (ht); and (3) chemical species transport: transport of diluted species (tds). A brief discussion of these modules and roughness parameters are given in Appendix B.

\subsubsection{Measurement Points in the Model}

Two sets of measurement points had been taken in the model. The first set of seven measurement points at the downwind side of the lake had been chosen to accurately represent the actual urban stations (data logging point) of the field measurement areas around Dhanmondi Lake, starting from over the water of the lake, to the edge of the lake, then gradually shifting deeper into the urban fabric. The second set of twenty-two measurement points were taken starting from the land-lake boundary at the upwind side of the lake to the land-lake border of the downwind side of the lake. Most of those points in the second set are at equal distance along the length of the lake. The variables measured in these points are air temperature, relative humidity, inversion layer thickness, fetch, and the horizontal component of the total energy flux (f). All these points are shown in Figure 5. 


\section{Results and Analysis of the Field Measurement}

The detailed analysis of the result for reference measurement at the Bangladesh Meteorological Department (BMD) is given in Appendix C. Both the air temperature and relative humidity in the reference measurement of BMD had shown a strong correlation with cumulative time. Still, the correlation was the opposite for air temperature and relative humidity. When considered as a continuous independent variable rather than a categorical value, time had a cumulative effect throughout the day and night on dependent variables like air temperature and relative humidity (RH) in terms of solar influx. The strong positive correlational value between cumulative time and air temperature showed that the rate of change in the solar influx was always positive during the daytime. However, the rate of solar influx varied throughout the day. Analysis of the related data from the field measurements at Dhanmondi Lake and Hatirjheel Lake urban stations is given in the following sections. Figure 6 indicates in general that the data logger, which was placed further away from the edge of the lake, exhibited more temperature but less humidity in comparison to the data logger located near the lake. However, it is evident from this analysis (Figure 6) that this effect was more pronounced in the lake with more riparian shading (in this case Dhanmondi Lake indicated by DM) than the lake with comparatively less shading (in this case Hatirjheel Lake shown by HJ).

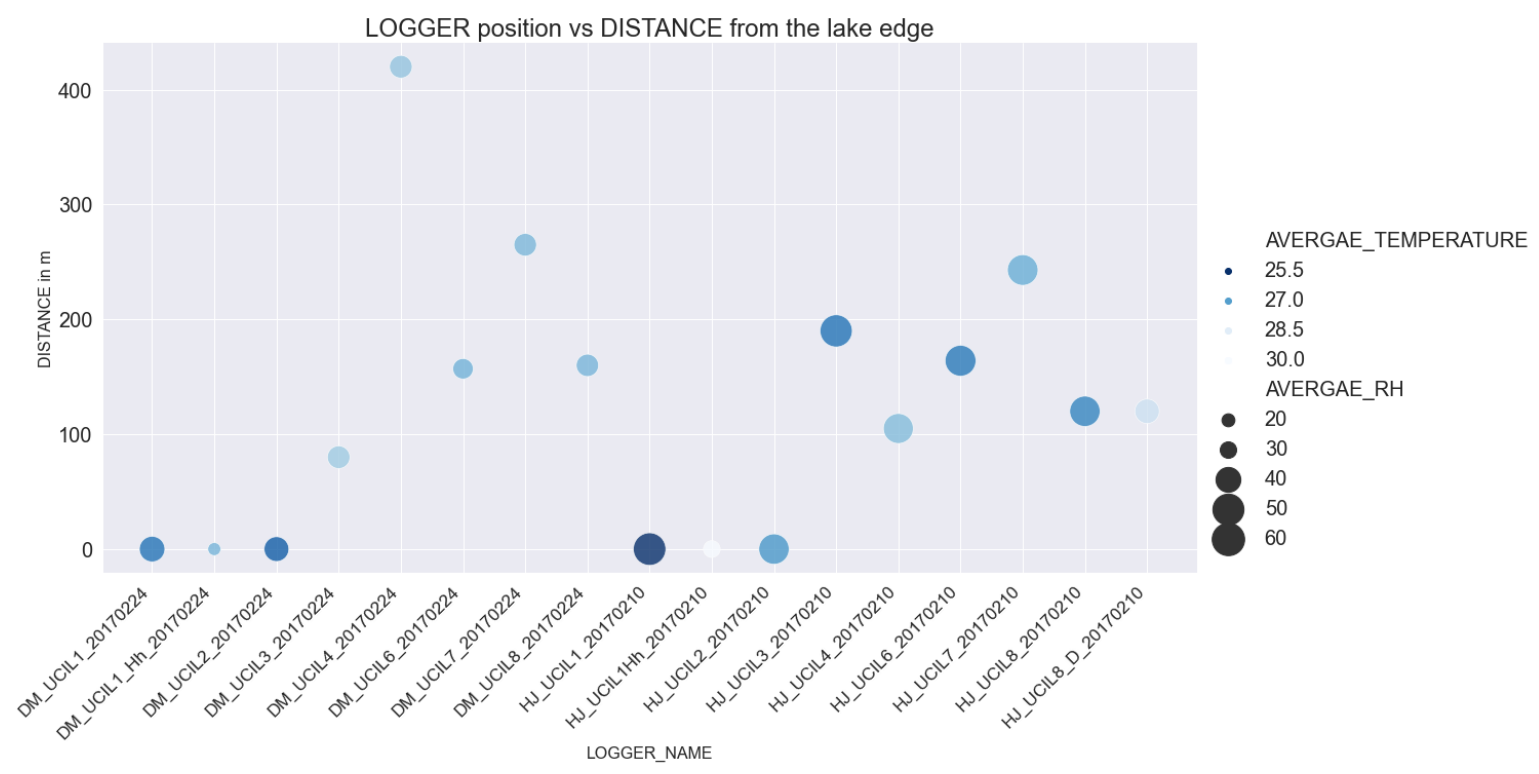

Figure 6. Relation of air temperature and relative humidity with the distance from the edge of the lake water.

\subsection{Lake Temperature}

On 21 October 2016, during the greatest hot spell of the day (Figure 7), which was at 3:25 p.m., UCILogger4 showed a maximum temperature of $35.5^{\circ} \mathrm{C}$ as it was on a road perpendicular to the wind direction from the lake. Among the urban stations placed on the road parallel to the wind direction, despite being the furthest station in the wind corridor, UCILogger7 was showing the significantly lower temperature of $32.5^{\circ} \mathrm{C}$, as it was receiving unhindered wind flow from the lake due to the wide and unobstructed road, whereas wind flow to UCILoggere6 $\left(34.0^{\circ} \mathrm{C}\right)$ was reduced by trees, a small road width, and other small manmade structures. In general, UCILogger4 showed higher temperatures throughout the day. The correlation coefficient between air temperature, relative humidity, and cumulative time for all the measurement days of the urban stations could be found in Appendix C. Overall, all the urban stations showed a positive correlation between air temperature and cumulative time. 

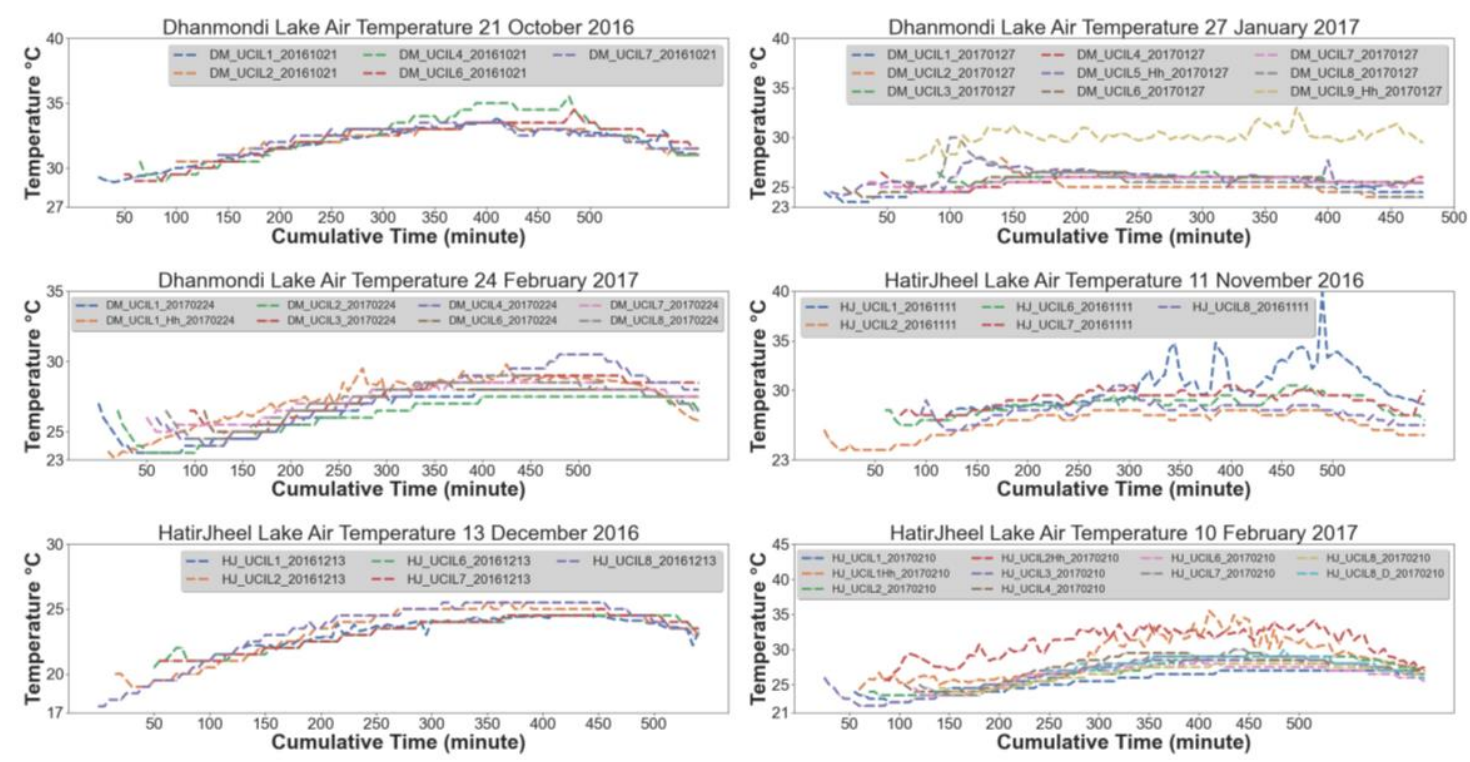

Figure 7. Air temperature over the edge and in the surrounding area of both the lakes at the measurement day.

Figure 7 also shows the temperature of the urban stations during the measurement campaign on 27 January 2017. Urban stations UCILogger9, located on an island with no riparian shading inside the lake, shows the maximum temperature throughout the day. Due to the sky becoming cloudy from 11:00 a.m. onwards on this measurement day, the temperature difference between the different urban stations reduced with respect to the previous measurement day. Even though urban station UCIL9, located in the island middle of the lake, had shown a higher temperature than the other stations throughout the day. One important thing to observe is that the correlation between air temperature and cumulative time was significantly changed due to the cloudy sky. Some urban stations UCIL2, 3, 5 , and 8 showed a negative correlation, which indicates the state of heat loss due to the absence of sun. On 24 February 2017, during the greatest hot spell of the day, which was between 3:35 p.m. and 4:20 p.m., UCILogger4 showed the maximum temperature of $30.5^{\circ} \mathrm{C}$ as it was in a road perpendicular to the wind direction from the lake. Urban station UCILogger2 showed lower temperatures throughout the day. Among the urban stations placed in the road parallel to the wind direction, UCILogger7 and 8 exhibited the higher temperatures of $28.5^{\circ} \mathrm{C}$ as they were located further away from the lake edge. The maximum temperature of the urban station at the island UCILogger 1 was $29^{\circ} \mathrm{C}$, which was $0.5^{\circ} \mathrm{C}$ higher than UCILogger7. In general, UCILogger4 showed greater temperature throughout the day. The correlation analysis between air temperature and cumulative time throughout the day shows heat gain with time for all the urban stations. It is important to note that the urban station at the small island and the water edge was on the higher side in terms of heat gain.

The observation result (Figure 7) on 11 November 2016, at the Hatirjheel Lake urban stations, demonstrated one of the advective effects named the "Oasis effect" in an urban area due to the presence of an urban park. The trees in the park reduced solar gain through shading and evapotranspiration. Otherwise, the Hatirjheel Lake area was mostly devoid of significantly large trees for evapotranspiration and shading at UCL. The urban station UCIL2, located at the edge of the park on the downwind side, showed an overall lower temperature than the others. The urban station UCIL1 showed a higher temperature with some unusual high peak due to the location being on the top of the water of the lake on a bridge without any shading. Additionally, the passing vehicles were contributing to a sudden peak in temperature. However, overall, UCIL1 shows higher temperatures. Despite being inside the fabric and without significant tree shading, UCIL8 showed comparatively lower temperatures due to the canyon shading at the UCL. The correlation analysis between cumulative time and air temperature for all the urban stations on 11 November 2016 showed a moderately positive correlation 
except for the urban station UCIL8. Being the furthest from the water edge, it proved almost zero correlation, which indicates neither heat gain nor heat loss. One reason is that due to its location on an urban canopy of the north-south elongated road at this time of the year, it stays mostly in the shade throughout the day. The urban stations in the middle of the lake and water edge showed a moderate correlation, which indicates solar gain throughout the day.

On 13 December 2016 (Figure 7), one of the urban stations, UCIL8, was at the Bangladesh meteorological department site with their instrument. This was done to consider it as a reference point and for calibration purposes. Among the four urban stations at the Hatiriheel Lake area, three stations, UCIL1, 6, and 7, were hung from a bridge in the middle of the lake at a different level from the top of the water surface. UCIL2 was placed at the edge of the park, like before, on the downwind side of the park. At the urban stations at the Hatirjheel Lake area, UCIL2 showed a maximum temperature during the hottest spell of the day. The urban stations in the middle of the water behaved similarly. The correlation analysis from the data of 13 December 2016 showed a strong relationship between cumulative time and air temperature in the case of the two urban stations nearest to the top of the surface of the lake water, which indicates positive solar gain. The urban stations at the park also showed a positive solar gain, although this was lesser than the former two. The air temperature data from the observation of the urban stations at Hatirjheel Lake on 10 February 2017 are presented in Figure 7. The minimum temperature at the time of hot spell was $27.5^{\circ} \mathrm{C}$ at the urban station UCIL6, and the maximum was $30^{\circ} \mathrm{C}$ at the urban station UCIL7. Urban station UCIL1 in the middle of the lake, hanging on the top of the water, showed a consistent increase in air temperature. However, the temperature stayed below the urban station on the land inside the urban fabric until the afternoon. However, it did not decrease like the other urban station on the ground inside the urban fabric in the late afternoon. Urban station UCIL2 at the water edge also followed the pattern of UCIL1. The correlational analysis of the air temperature data and cumulative time of Hatirjheel Lake urban stations on 10 February 2017, proved that the urban stations on the top of the water UCIL1 and at the edge of the water UCIL2 show the strongest positive correlation of air temperature with cumulative time, which means strong heat gain throughout the day due to the solar influx. This could be explained by the heat capacity of the water, which is higher than the land and air temperature near the water surface regulated by the temperature of the water surface. Water can contain high amounts of heat, and it has a very low albedo. So, with the beginning of the day, it absorbs heat without increasing the temperature quickly, like the urban hard surface. However, in the late afternoon, when the urban hard surface starts losing heat and thus decreases its temperature, the water surface does not exhibit similar rapidity in a temperature decrease. It stays relatively warmer than the land until late in the evening, as does the air layer near the water surface. That is why air temperature at the urban stations 1 and 2 are strongly positively correlated with cumulative time, which indicates strong solar gain. The two urban stations at the middle and edge of the urban park, UCIL8 and 3, also exhibited a strong positive correlation between air temperature and cumulative time and thus indicated strong heat gain due to the solar influx. The other three urban stations inside the urban fabric, UCIL4, 6, and 7, exhibited moderate positive correlation and thus indicated moderate heat gain due to the solar influx. Among these urban stations, heat gain increased with their distance from the water edge.

\subsection{Lake Relative Humidity}

On the measurement day of 21 October 2016 (Figure 8), the minimum humidity was observed throughout the day at the urban station UCILogger1 at the island inside the lake, which was contrary to the current assumption that humidity near and over the lake should be maximum. The maximum humidity observed throughout the day was at the urban stations UCILogger6 and 7. The urban station at UCILogger4 showed relatively less humidity than UCILogger6 and 7. The correlation calculated from the observation on 21 October 2016, between cumulative time and observed relative humidity (RH) indicates a negative correlation that is consistent with the reference observation made at the BMD site. This negative correlation indicates the positive rate of change in the solar influx throughout the 
day, which is opposite to the air temperature. For a particular point in the UCL, the more the heat gains due to the solar radiation, the lesser will be the RH. However, this positive solar gain could be affected by other factors such as advection and shading from trees or built fabric, which was evident from the observation. From the correlation coefficient, it is evident that the highest solar gain was at the urban station UCIL1, 4, and 6. The least solar heat gain was on the urban station UCIL7. As the sky became overcast from 11:00 a.m. onwards, the relative humidity ( $\mathrm{RH})$ measurement shows little difference. The correlation coefficient between cumulative time and $\mathrm{RH}$ calculated from the observation made on 27 January 2017 is presented in Table A5, which indicates the heat loss due to the absence of solar influx as the sky became overcast. Usually, in the daytime, the RH was negatively correlated with the cumulative time due to solar influx, although variable. However, as the sun disappears behind the cloud, direct solar gain stops immediately, and net radiative loss increases immediately, which is the case in all the urban stations except UCIL4 and 6. UCIL4 and 6 were deep in the urban fabric and devoid of airflow from the lake. However, due to heat storage by the fabric, they were still gaining heat although at a much slower rate than before.
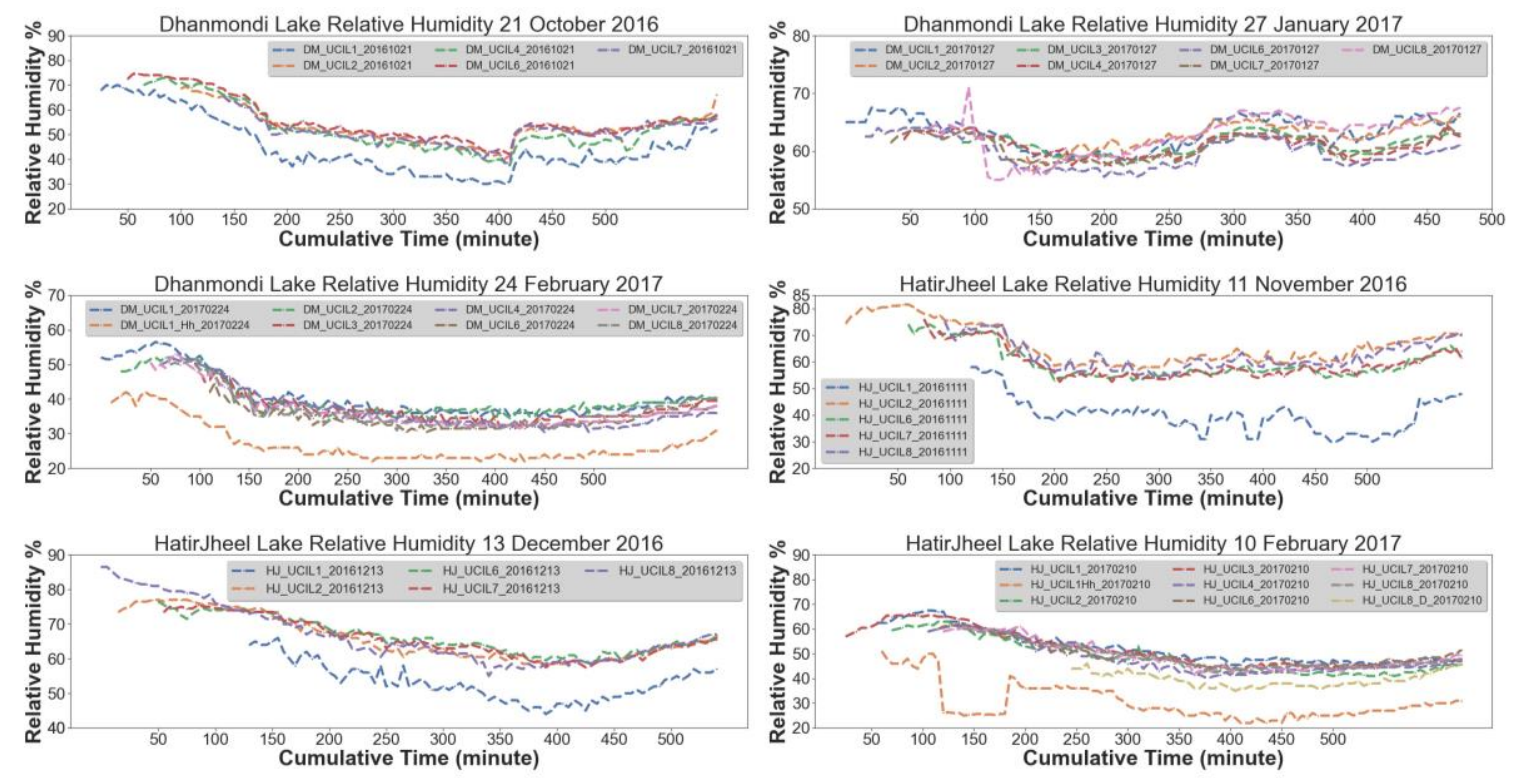

Figure 8. Relative humidity over the edge and in the surrounding area of both the lakes at the measurement day.

The observations at the urban stations made on 24 February 2017 are presented in Figure 8. In all the urban stations, relative humidity stays in its highest value at the starting of the day, which decreased as the day progressed. The rate of decrease ceased in the late afternoon at approximately 3:00 p.m. After 4:00 p.m., it started to increase until sunset slowly. The lowest humidity observed was $30.5 \%$ at 3:50 p.m. at urban station four, which was the furthest inside the urban fabric. From the correlation coefficient calculated from the 24 February 2017 observation of the urban stations, all the urban stations are showing a negative correlation with humidity change with cumulative time. This indicates heat gain due to solar influx throughout the day and thus the drop in RH. Maximum heat gain and thus increased rate of RH drop was identified at the urban stations UCIL4 deep in the urban fabric. The second-highest rate of RH drop was observed at the island urban station UCIL1. The UCIL 6, 7, and 8 stations show comparatively less RH drop as they were getting moist air directly from the lake, and the RH drop increased with the distance. From the relative humidity $(\mathrm{RH})$ data (Figure 8 ) of the measurement at urban stations at Hatirjheel Lake on 11 November 2016, the overall lowest RH was observed at urban station UCIL1 throughout the day. Overall higher RH was found by the UCIL2 located at the edge of the urban park on the downwind side. Urban station UCIL6 at the water edge also showed overall lower RH throughout the day. The correlation analysis (Table A10) between RH 
and the cumulative time of the data from the urban stations at Hatiriheel Lake on 11 November 2016, showed the urban stations at the water edge, top of the water, and the park was negatively correlated with the correlation strength being moderate. The other two stations in the urban fabric also show a negative correlation. UCIL8 showed the least negative correlation for $\mathrm{RH}$, which indicates the least heat gain throughout the day.

Figure 8 shows the relative humidity data from the urban stations at Hatirjheel Lake on 13 December 2016. Overall, the first urban stations on the top of the water surface showed low relative humidity throughout the day.

The correlational analysis in between cumulative time and relative humidity data from the urban stations at Hatirjheel Lake on 13 December 2016, showed a negative correlation throughout the day for all the stations, which is in correspondence with the reference urban station at the BMD site. The negative correlation is strong at the urban stations nearer to water surface UCIL6 and 7. The urban station at the edge of park UCIL2 also shows a strong negative correlation, which indicates strong positive heat gain by air due to solar influx throughout the day. Figure 8 also shows the relative humidity data from the urban stations at Hatirjheel Lake on 10 February 2017. Overall, all the urban stations showed a decline of relative humidity as the day progressed, which evened out from the afternoon to late afternoon. Relative humidity again continued to increase slowly in the late afternoon. Urban station UCIL2 at the edge of the water surface started showing lower relative humidity than the other stations starting from the afternoon until sunset. The humidity at the urban station UCIL1 on top of the water surface declined relative to other urban stations on the ground from the afternoon until sunset. The correlational analysis between cumulative time and relative humidity data of the urban stations of Hatirjheel Lake on 10 February 2017 is presented in Table A15 and indicates an overall negative correlation at all urban stations. This correlational analysis clearly showed the strongest negative correlation between cumulative time and relative humidity at the urban station on top of the water UCIL1 and at the water edge UCIL2, which indicates a decrease in relative humidity due to the high heat gain of water due to solar influx throughout the day. The urban stations in the middle of park UCIL8 and at the edge of the park UCIL3 also showed a strong negative correlation. The other three urban stations inside the urban fabric UCIL4, 6, and 7, also showed a strong negative correlation, although to some lesser extent than the previous four stations at the top of the water and the park near the water edge.

\subsection{Key Observations from Field Measurement}

Several important observations could be made from the analyzed field measurement data obtained from the selected urban stations on both the wetlands discussed in the previous section.

i. Effect of cumulative time on the rate of change of air temperature and relative humidity:

The study shows that time, if considered as an increasing quantity rather than a categorical value, had a cumulative effect on the rate of change of air temperature and relative humidity in terms of solar influx. At night, due to the absence of solar influx, the air temperature had an almost negative linear relationship with cumulative time and relative humidity $(\mathrm{RH})$ had a nearly positive linear relationship with cumulative time. During the day, with the presence of a solar influx, although variable, the time cumulative effect was reversed. In the daytime, the air temperature had a strong positive correlation with cumulative time, and relative humidity had a strong negative correlation with cumulative time.

ii. Effect of riparian shading on the cumulative time effect:

In the case of urban wetland devoid of riparian shading, the cumulative effect of time was strongest at the top and near the edge of the wetland, which was evident from the analysis of the field data measured at Hatirjheel Lake urban stations. In the case of the Dhanmondi Lake area, the cumulative effect of time was relatively weaker than that of the Hatirjheel Lake area. 
iii. Influence of the distance from the edge of the wetland on temperature:

Air temperature dropped as much as $3{ }^{\circ} \mathrm{C}$ during the maximum hot spells of the day in those urban stations, which were located on the road parallel to the wind flow (logger named "DM_UCIL7" in case of Dhanmondi Lake) from the wetland when the built forms or natural features did not obstruct the wind flow. This effect was more pronounced in the case of Dhanmondi Lake than Hatirjheel Lake. The temperature on the urban station increased with distance from the lake edge. The urban station (logger named "DM_UCIL4" in case of Dhanmondi Lake) located on the road perpendicular to the prevailing wind direction from the lake exhibited a higher temperature.

iv. Effect of the location of the park on temperature:

The existence of an urban park creates an "oasis effect" by moderating temperature and increasing humidity, which is the case in the Hatirjheel Lake area. Hatirjheel Lake is mostly devoid of large vegetation in its surroundings. However, the existence of the urban park creates a small "oasis effect" by showing almost average $4.5^{\circ} \mathrm{C}$ lower temperature then the urban station (logger named HJ_UCIL2Hh in case of Hatirjheel Lake) showing maximum average temperature.

v. Effect of shading in the urban canyon:

Urban stations that are located in the urban canyon shaded most of the time by the canyon itself showed decreased temperature.

vi. Humidity and distance from the lake edge:

Relative humidity $(\mathrm{RH})$ near the edge of the water and over the water was lower than the park and vegetated area, which is consistent with the findings of Geiger (2009).

vii. Evaporative cooling potential:

Another important observation is that with the progress of the day, relative humidity decreased, which dipped significantly from mid-day to late afternoon. This phenomenon of the relative humidity increased the evaporative cooling potential.

\section{Results and Analysis of Simulation Study}

The detailed analysis of the data from the simulation results is given in the following sections.

\subsection{Effect of Shading on Water Temperature}

A simulation study was conducted at a section of the Dhanmondi Lake area (approximately $468 \mathrm{~m} \times 280 \mathrm{~m}$ ) adjacent to Satmasjid road (on the south-west), and road 6A (on the south-east) was selected. One of the days of field measurement in this area, 24 February 2017, was used for the sun position in the simulation model. The simulation time was fixed from 9 a.m. to 4:00 p.m. of that day. The whole simulation study was conducted for three cases depicting three types of ambient condition:

a. Case 1: First simulation study conducted with the water of the lake entirely under solar radiation.

b. Case 2: Second simulation study conducted with fifty percent (50\%) water of the lake under solar radiation.

c. Case 3: Third simulation study conducted with the water body completely shaded from solar radiation.

The simulation was conducted using COMSOL-Multiphysics software version 5. Heat transfer module-heat transfer with surface to surface radiation (ht) of COMSOL-Multiphysics was used in the simulation. The initial temperature of the water was fixed at the level equal to the minimum temperature of the day obtained from the field measurement. A detailed description of the model is 
given in Section 2.2. Below, Figure 9 depicts the effect of shading on the water surface temperature of the lake.

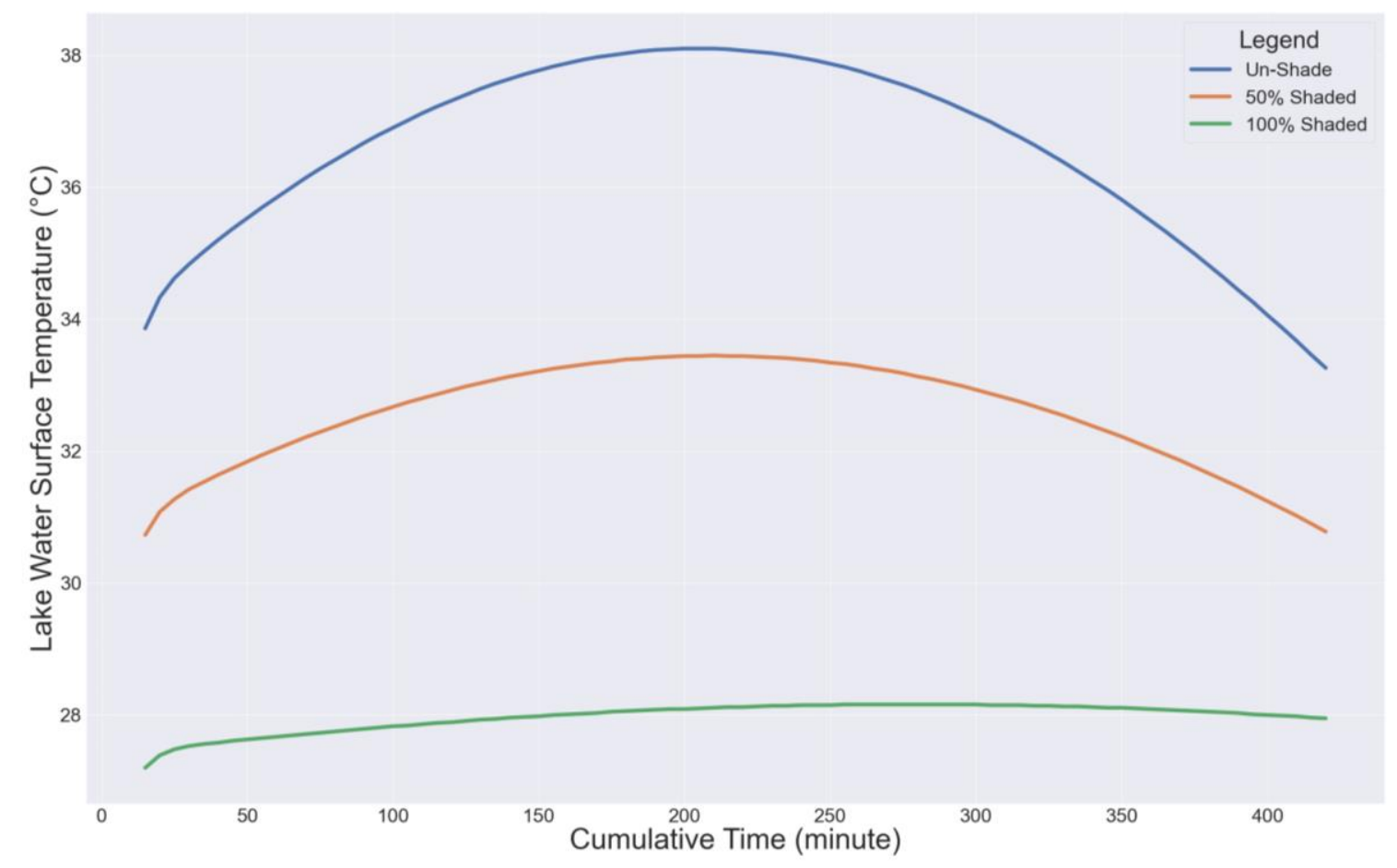

Figure 9. Effect of shading on simulated water surface temperature of the lake.

From the simulation study, it could concur that the fully shaded water surface reacted little to the progressing day temperature as, in this case, the waterbody can only gain heat from the ambient temperature of the atmosphere.

\subsection{Effect of Cumulative Time on the Rate of Change of Air Temperature and Relative Humidity}

When time is considered as a continuous variable rather than a categorical value, we got the cumulative effect of time on the rate of change of air temperature and relative humidity. Temperature and relative humidity (RH) data at the first set of seven points in each of the four cases were extracted, and correlation analysis was done in the R-studio using R programming language considering time as a continuous independent variable to see its cumulative effect.

The correlation analysis of the four cases strongly corresponds with the result of field measurement at the two lake areas and reference measurement at the Bangladesh Meteorological Department (BMD). It has been observed from the field study that time was considered as a continuous variable (an increasing quantity rather than a categorical value) that had a cumulative effect on the rate of change of air temperature and relative humidity in terms of solar influx. In all four cases, the rate of change in air temperature strongly and positively correlated with time (Figure 10). In the case of relative humidity, it is mostly negatively correlated, with the measurement point deep inside the urban fabric (UCIL4 and UCIL7) showing the strongest negative correlation. The measurement points near and over the water of the lake revealed a weak negative or weak positive correlation with time, which corresponds to the field measurement of both the lake areas. (Figure 11). 

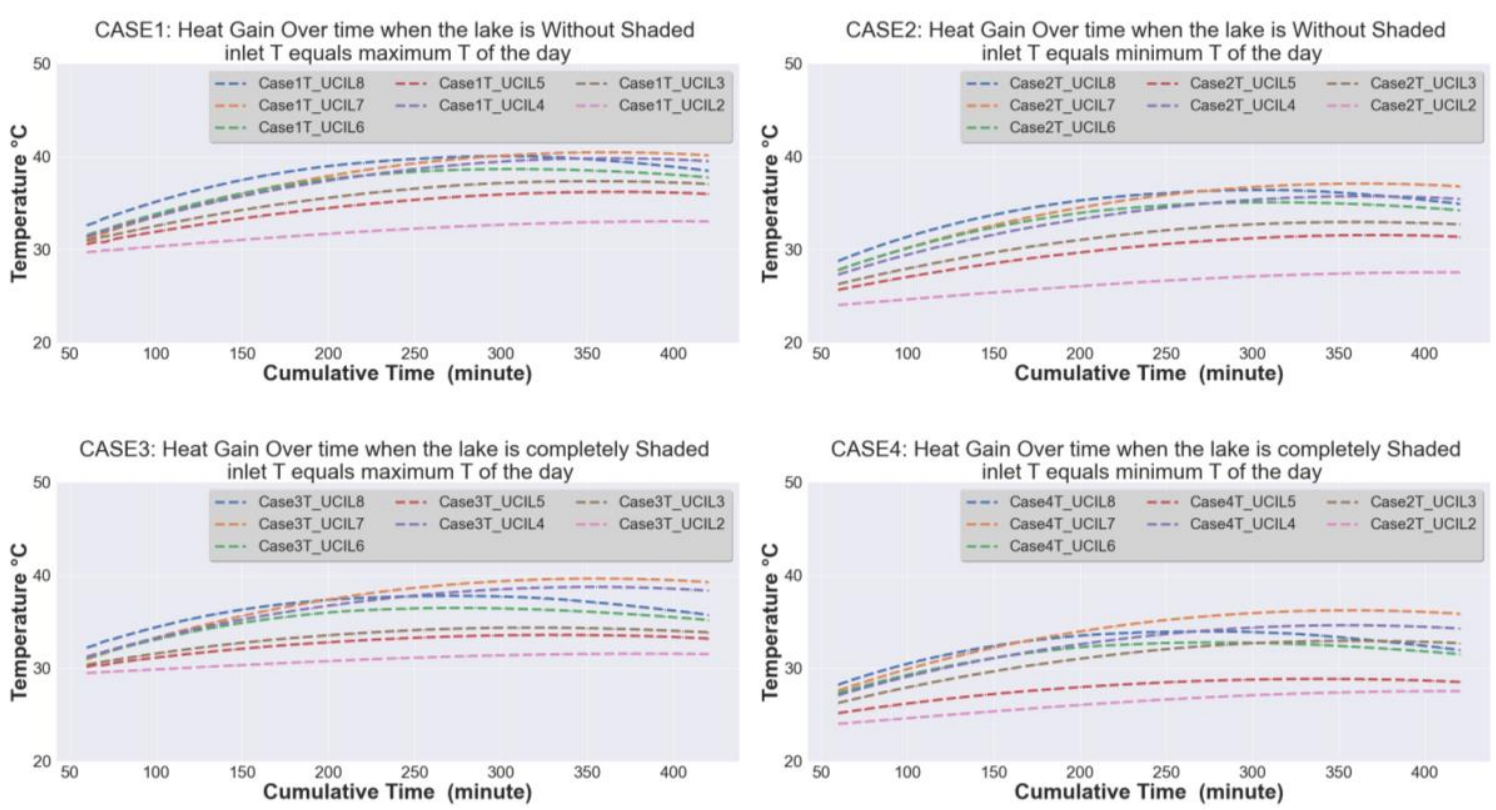

Figure 10. Effect of shading on simulated water surface temperature of the lake.
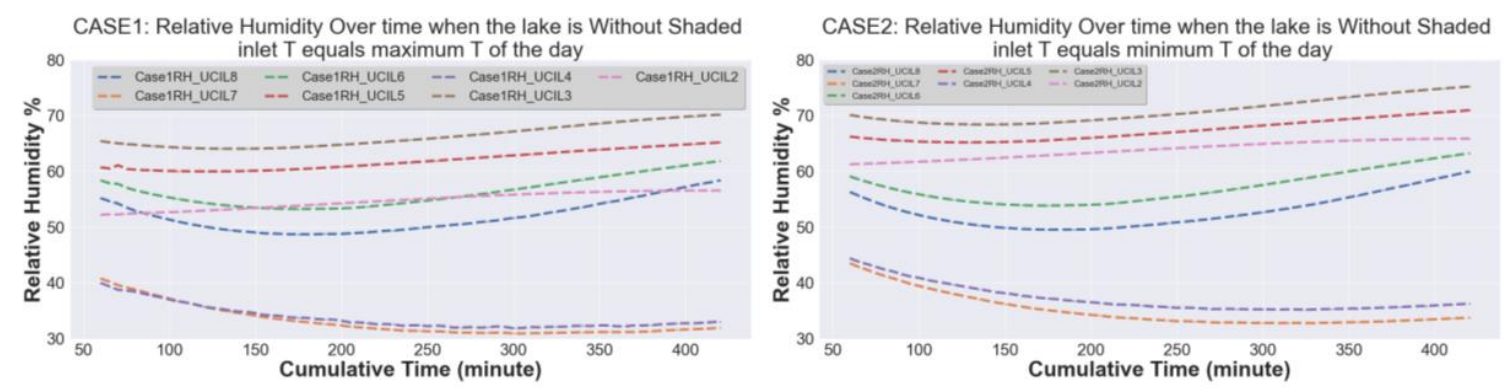

CASE3: Relative Humidity Over time when the lake is completely Shaded

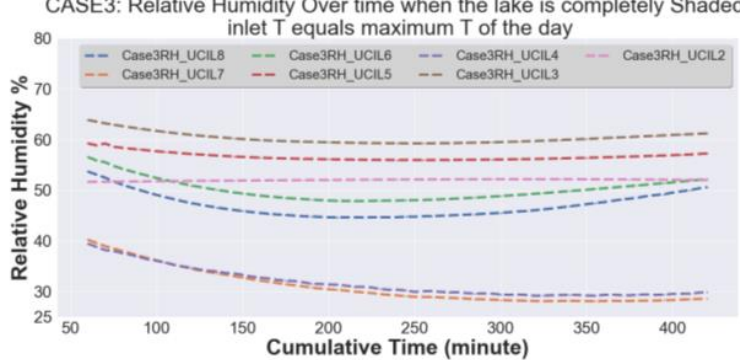

CASE4: Relative Humidity Over time when the lake is completely Shaded

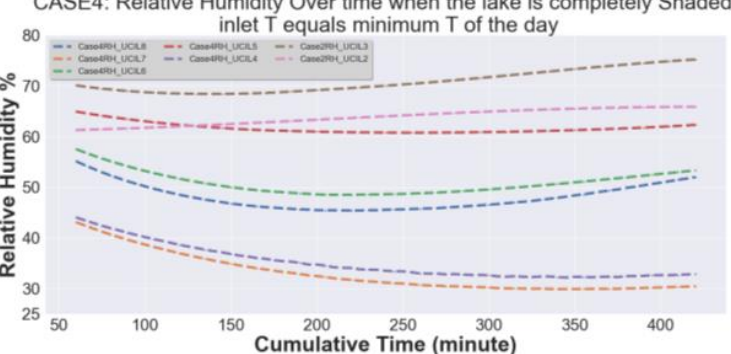

Figure 11. Effect of shading on simulated relative humidity above the water surface of the lake.

\subsection{Development of Inversion Layer}

Fraedrich (1972) [13] observed a shallow, stably stratified layer over the water of the lake, which he named the "inversion layer". This layer is produced by a negative downward flux over a water surface when the air is blowing from the warmer land. Additionally, if the advected air is relatively dry, evaporative cooling amplifies the stable inversion layer. The inversion can also happen even if the air temperature of the environment is equal or less compared with the temperature of the water surface at the shore. The reason for this is that the interaction between the air and the water varies (decreases) the water surface temperature along the air trajectory. The inversion layer also increasingly suppresses the evaporation from the lake, which increases with the travel distance of the air over the lake by creating a "Vapor blanket". 
All these phenomena mentioned above observed by Fraedrich were demonstrated in the four cases of the simulation study. All the conditions of the creation of the "inversion layer" were covered by the four cases of the simulation study.

Case 1: In the first case, the water of the whole lake was under complete solar radiation with inlet temperature equaling the maximum temperature of the day. The starting relative humidity (RH) of the simulation was set at equal of the RH observed at 9:00 a.m. on February 24 in the Dhanmondi Lake area. The simulation showed (Figure 12) a clear inversion layer above the water surface of the lake. The inversion layer was slightly advected towards the downwind side of the lake above the ground.
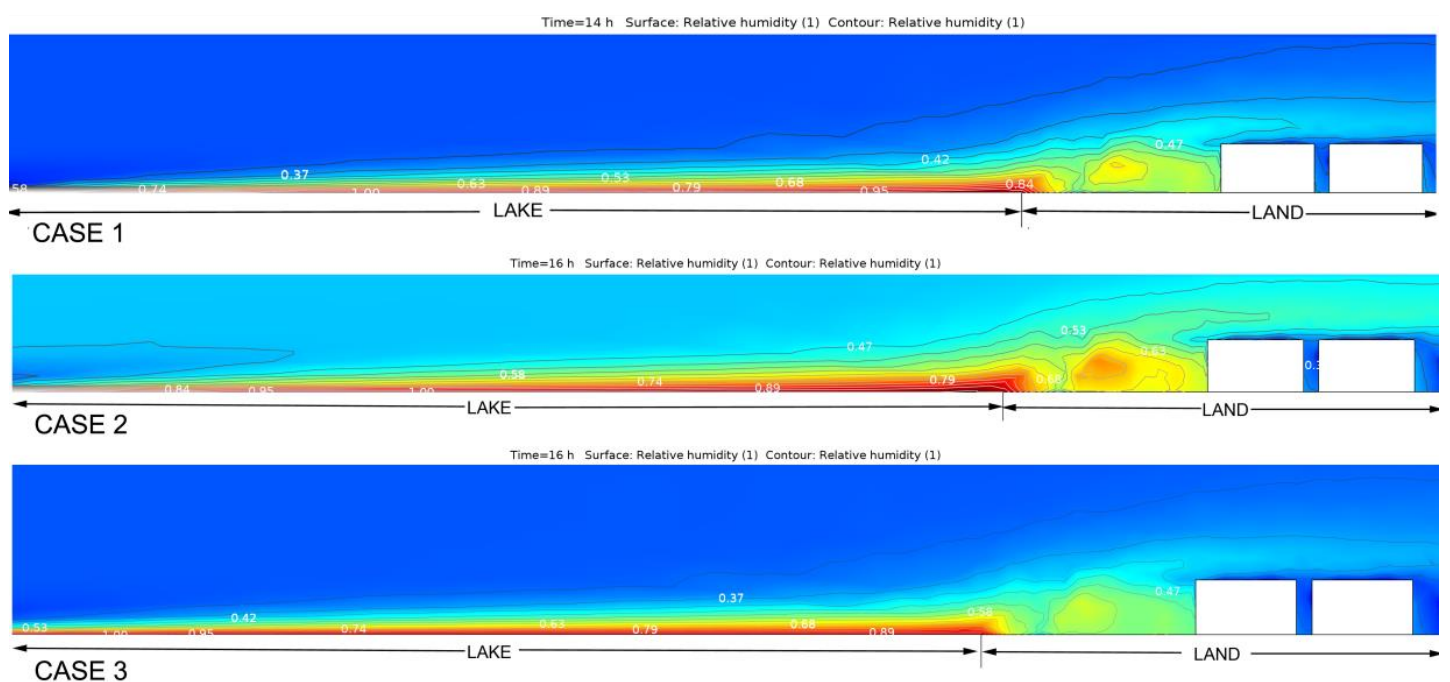

Time $=16 \mathrm{~h}$ Surface: Relative humidity (1) Contour: Relative humidity (1)

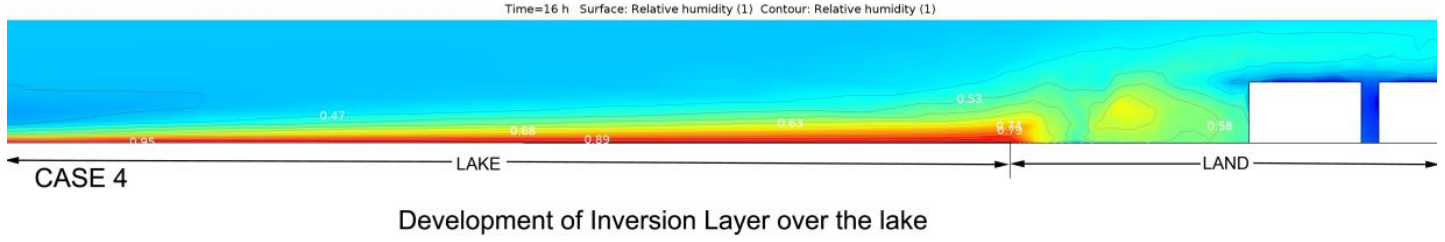

Figure 12. Inversion layer above the lake.

Case 2: In the second case, the water of the whole lake was under complete solar radiation with inlet temperature equaling the minimum temperature of the day. The starting relative humidity (RH) of the simulation was set equal to the RH observed at 9:00 a.m. on February 24 in the Dhanmondi Lake area. The simulation showed (Figure 12) a clear inversion layer above the water surface of the lake. The inversion layer was slightly advected towards the downwind side of the lake above the ground.

Case 3: In the third case, the water of the whole lake was shaded entirely from solar radiation with inlet temperature equaling the maximum temperature of the day. The starting relative humidity (RH) of the simulation set equal to the RH observed at 9:00 a.m. on February 24 in the Dhanmondi Lake area. The simulation showed (Figure 12) a clear inversion layer above the water surface of the lake. The inversion layer was slightly advected towards the downwind side of the lake above the ground, although this advection was less than case 1 and 2. Additionally, the thickness of the inversion layer was less than case 1 and 2.

Case 4: In the fourth case, the water of the whole lake was shaded entirely from solar radiation with inlet temperature equaling the minimum temperature of the day. The starting relative humidity (RH) of the simulation set equal to the RH observed at 9:00 a.m. on February 24 in the Dhanmondi Lake area. The simulation showed (Figure 12) a clear inversion layer above the water surface of the lake. The inversion layer was slightly advected towards the downwind side of the lake above the ground, although this advection is less than case 1 and 2. Additionally, the thickness of the inversion layer was less than case 1,2 , and 3. 


\subsection{Effect of the Fetch on the Inversion Height}

A strong relationship between the inversion height and the fetch was observed in all the four cases. Fetch is the distance starting from the land-lake boundary of the downwind side of the lake to the upwind side towards the wind flow direction. Inversion height was the maximum thickness of the inversion layer (fully saturated with water vapor) at a particular point over the lake (Figure 13).

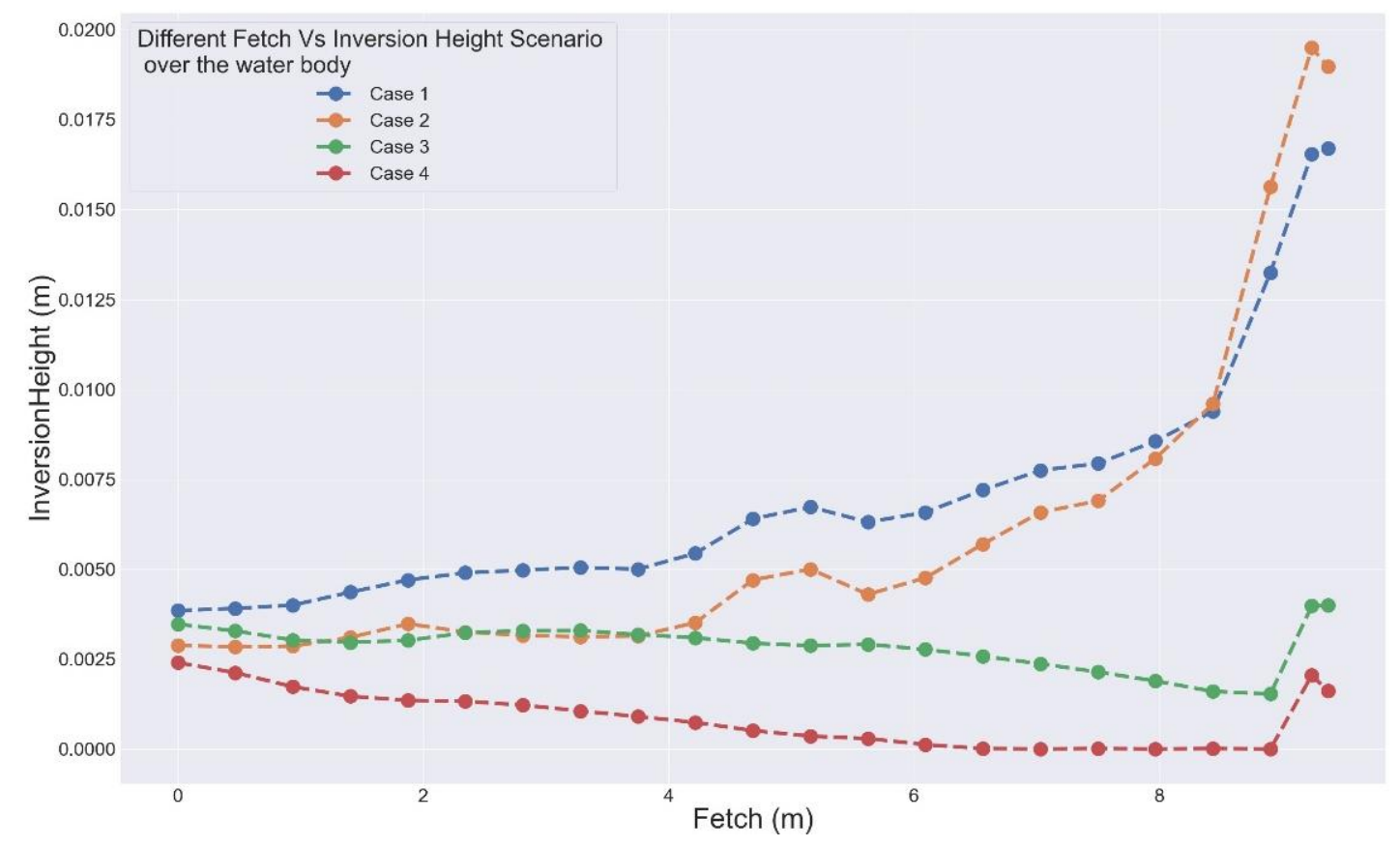

Figure 13. Case 1-inversion height $\mathrm{z}$ versus fetch $\mathrm{x}$.

Case 1: In the first case, the water of the whole lake was under complete solar radiation with inlet temperature equaling the maximum temperature of the day. In this case, the inversion layer increased in height with the increasing fetch (Figure 13).

Case 2: In the second case, the water of the whole lake was under complete solar radiation with inlet temperature equaling the minimum temperature of the day. In this case, the inversion layer increased in height with the increasing fetch (Figure 13), although this increase was less than case 1.

Case 3: In the third case, the water of the whole lake was shaded entirely from solar radiation with inlet temperature equaling the maximum temperature of the day. In this case, the inversion layer decreased in height with the increasing fetch (Figure 13).

Case 4: In the fourth case, the water of the whole lake was shaded entirely from solar radiation with inlet temperature equaling the minimum temperature of the day. In this case, the inversion layer decreased in height with the increasing fetch (Figure 13).

\subsection{Correlation between the Inversion Height and Fetch}

Table A20 in Appendix C shows the correlation between the inversion height and fetch. In the case of Cases 1 and 2, inversion height had a strong positive correlation with fetch, with Case 1 having the strongest positive correlation. Whereas in the case of Cases 3 and 4, the correlation was negative, with Case 4 having the strongest negative correlation.

This correlational analysis demonstrated the effect of riparian shading on the water temperature of the lake and hence the thickness of the inversion layer. It is clear from the study that urban wetlands with shade and less warm wind flow from the upwind will have a thinner inversion layer than the wetland with no shading and warmer inflow. Additionally, relative humidity $(\mathrm{RH})$ above the inversion layer of the lake will be less even compared with that of the land. This is the reason why in the 
field study, the urban stations over the water of the lake and the edge of the lake showed lower relative humidity $(\mathrm{RH})$ compared to the urban stations deep inside the fabric. Since, on average, urban stations above the water surface and edge of the lake were placed approximately $6 \mathrm{~m}$ above the water, those urban stations were above the inversion layer and hence showed lower $\mathrm{RH}$.

\subsection{Inversion Model}

A linear regression model was built based on the simulation model to test the relation between fetch, inversion layer thickness, temperature, and the horizontal component of total energy flux in the inversion layer. All the four cases described in this section were considered in the regression analysis. The variables included are:

i. Independent variable: fetch $(\mathrm{x})$;

ii. Dependent variables: inversion height (z), air temperature (T), relative humidity $(\mathrm{RH})$, and the horizontal component of the total energy flux (f).

From the simulation data, all the values of the variables were selected for fully saturated air, i.e., $100 \%$ relative humidity. The regression analysis was done in R-studio using the " $\mathrm{R}$ " programming language. The following are the regression models that describe the relationship:

Case 1: For Case 1, the regression model is:

$$
x=39.42+868.6928 z-1.319 T+0.003547 f
$$

From the model, it is evident that if the $\mathrm{T}$ and $\mathrm{f}$ are unchanged, increasing fetch will increase the inversion layer thickness.

Case 2: For Case 2, the regression model is:

$$
\mathrm{x}=43.02+740.7 \mathrm{z}-1.321 \mathrm{~T}+0.00004596 \mathrm{f}
$$

From the model, it is evident that if the $\mathrm{T}$ and $\mathrm{f}$ are unchanged, increasing fetch will increase the inversion layer thickness, although the increase will be less than that of Case 1.

From these two models, it is clear that we had to reduce fetch to reduce the thickness of the inversion layer and thus promote heat exchange between water and the air blowing above it. To reduce fetch, longer direction or length of the wetland should be perpendicular to the prevailing wind direction.

Case 3: For Case 3, the regression model is:

$$
x=3.317-491.1 z-0.3212 T+0.00004596 f
$$

From this model, it is evident that if the $\mathrm{T}$ and $\mathrm{f}$ are unchanged, increasing fetch will decrease the inversion layer thickness.

Case 4: For Case 4, the regression model is:

$$
x=-17.74-305.93952 z+1.0244 \mathrm{~T}-0.01463 \mathrm{f}
$$

From the model, it is evident that if the $\mathrm{T}$ and $\mathrm{f}$ are unchanged, increasing fetch will decrease the inversion layer thickness. This reduction will be higher than that of Case 3.

From these four models, it is evident that in an unshaded wetland, increasing fetch will increase the depth of the inversion layer. However, in a shaded wetland, increasing fetch will decrease the 
depth of the inversion layer, as the inversion layer decreases with increasing fetch and thus promotes heat exchange between water and the air blowing above it.

\subsection{Effect of the Relative Humidity on the Inversion Layer Thickness}

Two additional scenarios of relative humidity were considered for testing the relationship between the inversion height and the relative humidity both with Case 1 and Case 3 described previously.

Case 1: In the first case, the water of the whole lake was under complete solar radiation with inlet temperature equaling the maximum temperature of the day. Relative humidity $(\mathrm{RH})$ was equal to the starting RH obtained from the field measurement at 9:00 a.m., which was 51.5\%. In the first scenario of Case 1, the initial RH was set to 1.5 times of $\mathrm{RH}$ of the field measurement, which was $77.25 \%$. In the second scenario of Case 1, the initial RH was set to 0.5 times of $\mathrm{RH}$ of the field measurement, which was $25.75 \%$. The results obtained in the two scenarios of case 1 were plotted below in Figure 14. The results indicate the increase of the inversion layer thickness with increasing humidity from the upwind flow.

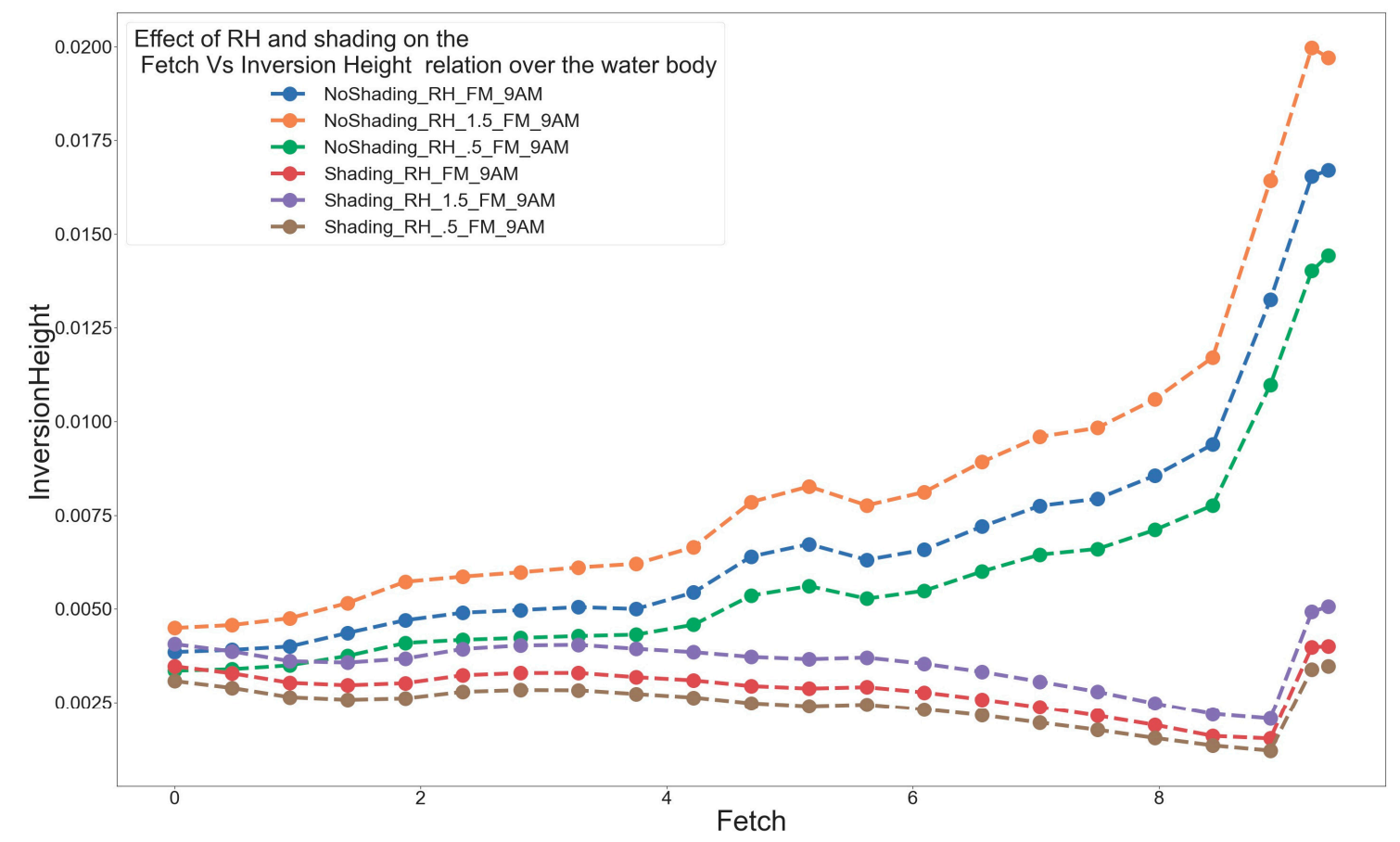

Figure 14. Case 1-Effect of relative humidity $(\mathrm{RH})$ on inversion height.

Case 3: In the third case, the water of the whole lake was shaded entirely from solar radiation with inlet temperature equaling the maximum temperature of the day. Relative humidity $(\mathrm{RH})$ was equal to the starting RH obtained from the field measurement at 9:00 a.m., which was 51.5\%. In the first scenario of Case 3, the initial RH was set to 1.5 times of $\mathrm{RH}$ of the field measurement, which was $77.25 \%$. In the second scenario of Case 3, the initial RH was set to 0.5 times of $\mathrm{RH}$ of the field measurement, which was $25.75 \%$. The results obtained from the two scenarios of Case 3 were plotted below in Figure 14. The results indicate the increase of the inversion layer thickness with increasing humidity from the upwind flow, although the water surface was entirely under shading.

\subsection{Effect of the Orientation and Riparian Shading Height of the Wetland on the Water Temperature}

The effect of orientation and shading height on the water surface temperature was simulated. The simulation time was 9:00 a.m. to 4:00 p.m. (Figure 15). 


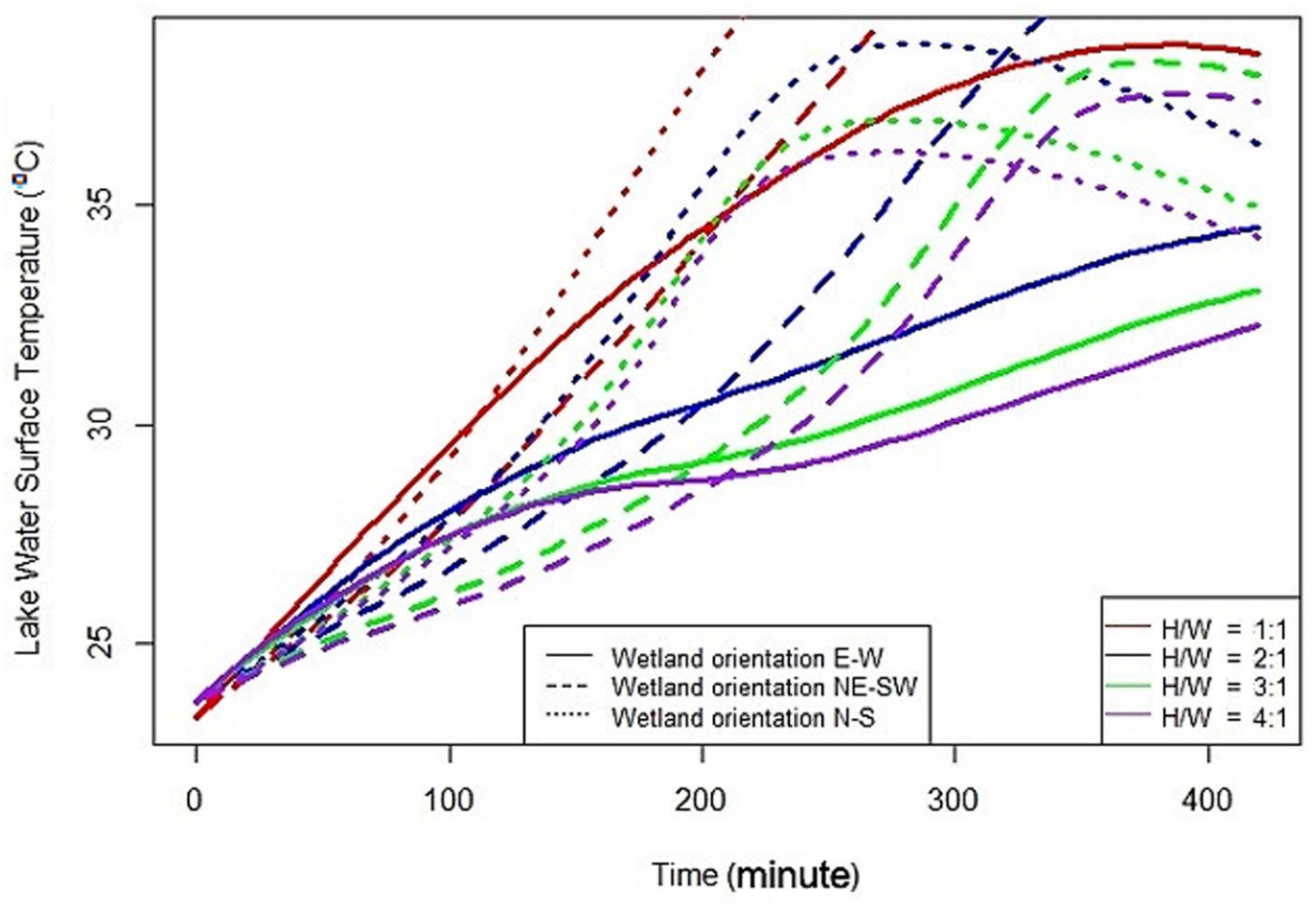

Figure 15. Effect of wetland orientation and the ratio of shading height $(\mathrm{H})$ vs. water surface width $(\mathrm{W})$ on the temperature of the water surface.

The date of the simulation was considered as February 24 to maintain consistency with the field measurement date of the Dhanmondi Lake area. For this simulation, a hypothetical wetland of linear shape with shading on both sides was considered. Four ratios between the shading height $(\mathrm{H})$ and wetland water surface width $(\mathrm{W})$ were found in conjunction with three orientations of the wetland. The ratios were $\mathrm{H} / \mathrm{W}=1, \mathrm{H} / \mathrm{W}=2, \mathrm{H} / \mathrm{W}=3$, and $\mathrm{H} / \mathrm{W}=4$. The three orientations of the long axis of the wetland considered were east-west $\left(90^{\circ}\right)$, north/east-south/west $\left(45^{\circ}\right)$, and north-south $\left(0^{\circ}\right)$. The result of the simulations is given in Figure 15. It can be concluded from Figure 15 that for the same amount of shading if the long axis of the wetland was oriented towards east-west (i.e., the wetland is more elongated towards east-west than north-south), it will be shielded more from the direct solar radiation, hence heat gain will be less. The wetland with a long north-south axis is less desirable in terms of shading from direct shortwave radiation from the sun. Although the increase in the $\mathrm{H} / \mathrm{W}$ ratio will provide better shielding against the direct solar radiation, together with the correct orientation, this high $\mathrm{H} / \mathrm{W}$ ratio will create optimal shading for the water of the wetland. Additionally, beyond $\mathrm{H} / \mathrm{W}$ ratio 2 , a further increase in shading height will not bring a significant benefit in terms of controlling the temperature of the water surface.

\section{Conclusions}

Urban wetlands are of paramount importance for their environmental functions besides their role in improving the aesthetic characteristics of urban places. However, to use the wetland in the urban fabric without considering its wide range of physical and morphological characteristics might create an unfavorable urban environment or may result in a loss of opportunity. Shading is essential for the wetlands of urban areas in the tropics, which could decrease temperature as much as $3^{\circ} \mathrm{C}$. Without necessary shading, the urban wetland will cease to play its role as a source of coolth for the urban fabric. Shading of the urban wetland could be achieved through typography, urban built form, and riparian shading. When the wetland is unshaded, the length of the "inversion layer" was found to be five times less in the case of urban wetland perpendicular to the wind direction than its parallel counterparts. The research work demonstrated the effect of a differential shading pattern on the relation between 
fetch and inversion layer thickness, opening avenues for designing retrofitting measures for architects, urban designers, and planners by way of landscaping interventions and modifications or amending building codes. So, an urban wetland with adequate riparian shading can render its essential role as an "Urban Cooling Island (UCI)". Based on the findings of the research an urban design matrix for urban wetlands was developed (given in Appendix D), which can contribute to design and planning thermally desirable urban bioclimate imperative in the warm-humid conditions of urban Dhaka as an adaptation measure against climate change. The effectiveness of the urban design guidelines presented in the design matrix for urban wetlands can help improve the bioclimate significantly if they form a part of the overall urban design scheme and urban development policy.

\section{Suggestions for Further Work}

Further works are required to investigate the behavior of urban wetlands in terms of its heat exchange with the atmosphere and with the land. This works needs to be carried out in the following two forms:

i. $\quad$ Field measurement:

Field measurement is required at multiple points, both at the horizontal and vertical direction, to capture the character of the inversion layer in detail. This measurement needs to be carried out on both diurnal basis and throughout the whole year in different seasons. In this study, the measurement point was only one or two points at the top and edge of the water with no robust measurement to capture the vertical profile of the variables, and this needs to gap in measurement needs to be addressed.

ii. Simulation work:

Due to the limited computational resources, the simulation model of the urban area was scaled down to a ratio of 1:50 and also simplified. So, to get an accurate understanding of the heat exchange mechanism of the urban wetland with its surroundings and atmosphere, a full-scale model simulation with as much possible detail is required. Additionally, the evapotranspiration of the tree was not included in the simulation model, which must be included to get an accurate scenario of the urban environment.

An appendix is uploaded with this manuscript containing necessary information of the research. The research data could be downloaded from the BUET Institutional Repository at the following web address: http://lib.buet.ac.bd:8080/xmlui/handle/123456789/4901.

Author Contributions: A.T.M.S. wrote the main manuscript text, prepared all figures and tables. All authors reviewed the manuscript. All authors have read and agreed to the published version of the manuscript.

Funding: This research received no external funding.

Acknowledgments: This paper is drawn from the Ph.D. research at the Department of Architecture, Bangladesh University of Engineering and Technology (BUET). Additionally, this paper was presented in a poster form in the "Symposium on Challenges in Applied Human Biometeorology that will take place on 2 and 3 March 2020 in Freiburg, Germany". The principal author received a travel grant from the Tromp Foundation to present the poster in the above-mentioned Symposium.

Conflicts of Interest: The authors declare no conflict of interest.

\section{Appendix A}

\section{Appendix A.1. Characteristics of the Urban Stations}

\section{Appendix A.1.1. Dhanmondi Lake Urban Stations}

The locations of the urban stations chosen for field measurement are shown on the Google Earth image (Figure A1). In the case of Dhanmondi Lake, all the urban stations except one (UCILogger4) were installed along the path of prevailing wind direction from the lake. The urban station UCILogger4 
was placed in a road deep inside the urban fabric, which was perpendicular to the prevailing wind direction. One urban station, UCIlogger1, was placed on a small island inside the lake.

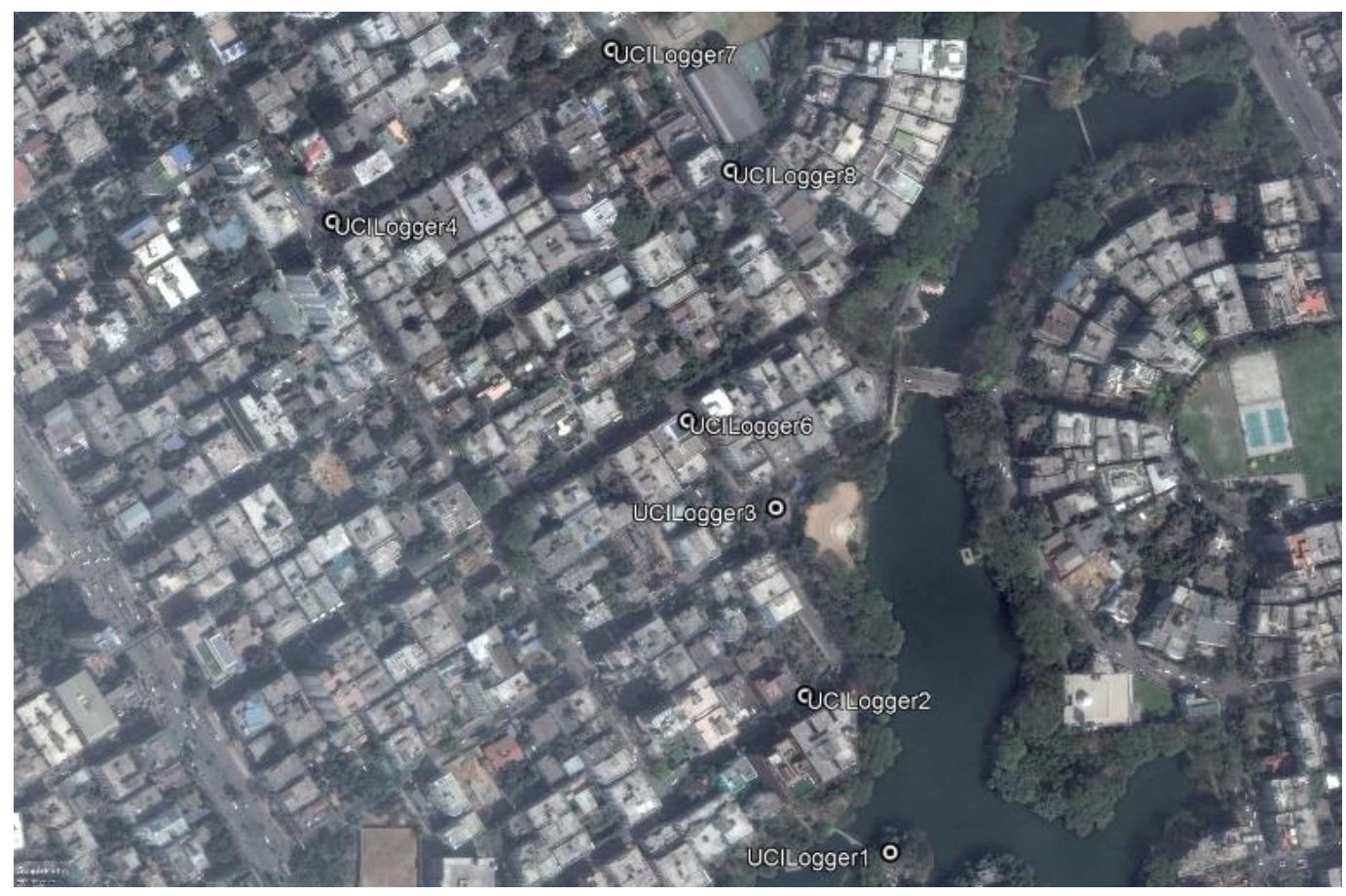

Figure A1. Location of the urban stations of field measurement at Dhanmondi Lake on 24 February 2017.

The following table (Table A1) provides detail information of each urban station on each measurement day of the Dhanmondi Lake area.

Table A1. Data logger location at Dhanmondi Lake area, 24 February 2017.

\begin{tabular}{|c|c|c|c|c|c|}
\hline S1 & Logger Name & $\begin{array}{l}\text { Location and Physical } \\
\text { Characteristics of Location }\end{array}$ & Location Photo & $\begin{array}{l}\text { Geographical } \\
\text { Coordinates }\end{array}$ & $\begin{array}{c}\text { Duration of the Data } \\
\text { Logging }\end{array}$ \\
\hline 1 & UCILogger1 & $\begin{array}{l}\text { Island in between road } 6 \mathrm{~A} \text { and } \\
\text { Sudha Sadan. } \\
\text { Ventilated Box mounted. On the } \\
\text { edge of a small island, in the middle } \\
\text { of the lake under tree shade. } \\
1 \mathrm{~m} \text { from the ground surface, tied } \\
\text { with a branch of shrubs }\end{array}$ & & $\begin{array}{l}\text { Latitude } \\
23.743302 \\
\text { Longitude } \\
90.377449\end{array}$ & $\begin{array}{l}\text { Start } \\
\text { 7:35 a.m. } \\
\text { Finish } \\
\text { 6:00 p.m. }\end{array}$ \\
\hline 2 & $\begin{array}{l}\text { UCILogger1-Extech } \\
\text { Dual Sensor }\end{array}$ & $\begin{array}{l}\text { Island in between road } 6 \mathrm{~A} \text { and } \\
\text { Sudha Sadan. } \\
\text { Handheld. On the edge of a small } \\
\text { island, in the middle of the lake } \\
\text { under tree shade. } \\
1 \mathrm{~m} \text { from the ground surface, tied } \\
\text { with a branch of shrubs }\end{array}$ & & $\begin{array}{l}\text { Latitude } \\
90.377449 \\
\text { Longitude } \\
23.743302\end{array}$ & $\begin{array}{l}\text { Start } \\
\text { 7:45 a.m. } \\
\text { Finish } \\
\text { 6:00 p.m. }\end{array}$ \\
\hline 3 & UCILogger2 & $\begin{array}{l}\text { Rabindra Sorobor; water edge; tied } \\
\text { to the branch of a banyan tree. } \\
\text { Ventilated box mounted. } 0.8 \mathrm{~m} \text { from } \\
\text { the top of the water surface. }\end{array}$ & Whing & $\begin{array}{l}\text { Latitude } \\
23.744261 \\
\text { Longitude } \\
90.376882\end{array}$ & $\begin{array}{l}\text { Start } \\
\text { 7:55 a.m. } \\
\text { Finish } \\
\text { 6:00 p.m. }\end{array}$ \\
\hline
\end{tabular}


Table A1. Cont.

\begin{tabular}{|c|c|c|c|c|c|}
\hline Sl & Logger Name & $\begin{array}{l}\text { Location and Physical } \\
\text { Characteristics of Location }\end{array}$ & Location Photo & $\begin{array}{c}\text { Geographical } \\
\text { Coordinates }\end{array}$ & $\begin{array}{c}\text { Duration of the Data } \\
\text { Logging }\end{array}$ \\
\hline 4 & $\begin{array}{l}\text { UCILogger2-Extech } \\
\text { Thermo-anemometer }\end{array}$ & $\begin{array}{c}\text { Rabindra Sorobor water. Handheld. } \\
1.5 \mathrm{~m} \text { from the top of the } \\
\text { ground surface. }\end{array}$ & & $\begin{array}{l}\text { Latitude } \\
23.744261 \\
\text { Longitude } \\
90.376882\end{array}$ & $\begin{array}{l}\text { Start } \\
\text { 11:50 a.m. } \\
\text { Finish } \\
\text { 6:00 p.m. }\end{array}$ \\
\hline 5 & UCILogger3 & $\begin{array}{l}\text { Rabindra Sorobar restaurant, } \\
\text { Junction of road 7A. } \\
\text { Ventilated Box mounted (at } 1.8 \mathrm{~m} \\
\text { height) under the shade of a tree, } \\
\text { exposed to direct air from the lake; } \\
80 \mathrm{~m} \text { from the edge of the water in } \\
\text { the north-western direction. }\end{array}$ & & $\begin{array}{c}\text { Latitude } \\
23.745408 \\
\text { Longitude } 90.376686\end{array}$ & $\begin{array}{l}\text { Start } \\
\text { 9:10 a.m. } \\
\text { Finish } \\
\text { 6:00 p.m. }\end{array}$ \\
\hline 6 & UCILogger4 & $\begin{array}{l}\text { The crossing of Road } 8 \mathrm{~A} \text { and } 10 \mathrm{~A} \text {. } \\
\text { Ventilated Box mounted (at } 1.8 \mathrm{~m} \\
\text { height) in a partly grass-covered } \\
\text { ground surface under the shade of a } \\
\text { tree, deep in the urban fabric with no } \\
\text { direct air corridor from the lake to } \\
\text { the point. Approximately at a } \\
\text { distance of } 420 \text { m directly from the } \\
\text { edge of the lake water in the } \\
\text { north-eastern direction } \\
\text { (heading } 112 \text { degrees). }\end{array}$ & & $\begin{array}{c}\text { Latitude } \\
23.747157 \\
\text { Longitude } \\
90.373729\end{array}$ & $\begin{array}{l}\text { Start } \\
\text { 8:32 a.m. } \\
\text { Finish } \\
\text { 6:00 p.m. }\end{array}$ \\
\hline 7 & UCILogger6 & $\begin{array}{l}\text { Road 8A near Rabindra Sorobor. } \\
\text { Ventilated box mounted (at } 1.8 \mathrm{~m} \\
\text { height) on paved footpath under the } \\
\text { shade of a tree; two air corridors } \\
\text { from the lake: } 120 \mathrm{~m} \text { from the edge } \\
\text { of the water in the north-eastern } \\
\text { direction. } 120 \mathrm{~m} \text { in the south-eastern } \\
\text { direction. } 157 \mathrm{~m} \text { directly from } \\
\text { the edge. }\end{array}$ & & $\begin{array}{l}\text { Latitude } \\
23.745942 \\
\text { Longitude } \\
90.376096\end{array}$ & $\begin{array}{l}\text { Start } \\
\text { 9:25 a.m. } \\
\text { Finish } \\
\text { 6:00 p.m. }\end{array}$ \\
\hline 8 & UCILogger7 & $\begin{array}{l}\text { Junction Road } 10 \mathrm{~A} \text { and Sultana } \\
\text { Kamal Mohila Complex. Ventilated } \\
\text { Box mounted (at } 1.6 \mathrm{~m} \text { height) in a } \\
\text { partly grass-covered ground surface } \\
\text { under the shade of a tree, with a } \\
\text { direct air corridor from the lake to } \\
\text { the point. Approximately } 265 \mathrm{~m} \\
\text { distance from the edge of the lake } \\
\text { water along the air corridor in the } \\
\text { north-eastern direction. }\end{array}$ & & $\begin{array}{l}\text { Latitude } \\
23.748209 \\
\text { Longitude } \\
90.375590\end{array}$ & $\begin{array}{l}\text { Start } \\
\text { 8:25a.m. } \\
\text { Finish } \\
\text { 6:00 p.m. }\end{array}$ \\
\hline 9 & UCILogger8 & $\begin{array}{l}\text { At the junction between road 9A and } \\
11 \mathrm{~A} \text {, south-west corner of Sultana } \\
\text { Kamal Mohila complex. } \\
\text { Height } 1.6 \mathrm{~m} \text { from the footpath. } \\
160 \mathrm{~m} \text { from the edge of the water in } \\
\text { the north-western direction. }\end{array}$ & & $\begin{array}{l}\text { Latitude } \\
23.747469 \\
\text { Longitude } \\
90.376386\end{array}$ & $\begin{array}{l}\text { Start } \\
\text { 8:45 a.m. } \\
\text { Finish } \\
\text { 6:00 p.m. }\end{array}$ \\
\hline
\end{tabular}

\section{Appendix A.1.2. Hatirjheel Lake Urban Stations}

In the case of Hatirjheel Lake, one urban station UCILogger1 was suspended from the middle of the Mahanagar Bridge above the water of the lake. Urban station UCILogger2 was placed beside the lake edge. Two urban stations (UCILogger8 and 3) were placed inside and at the edge of the park beside the lake. The rest of the urban stations were placed along a road parallel to the prevailing wind direction. All the locations of the urban stations except UCILogger1 could be seen in the Google Earth image of Figure A2.

The following table (Table A2) provides detailed information about each urban station on each measurement day of the Hatirjheel Lake area. 


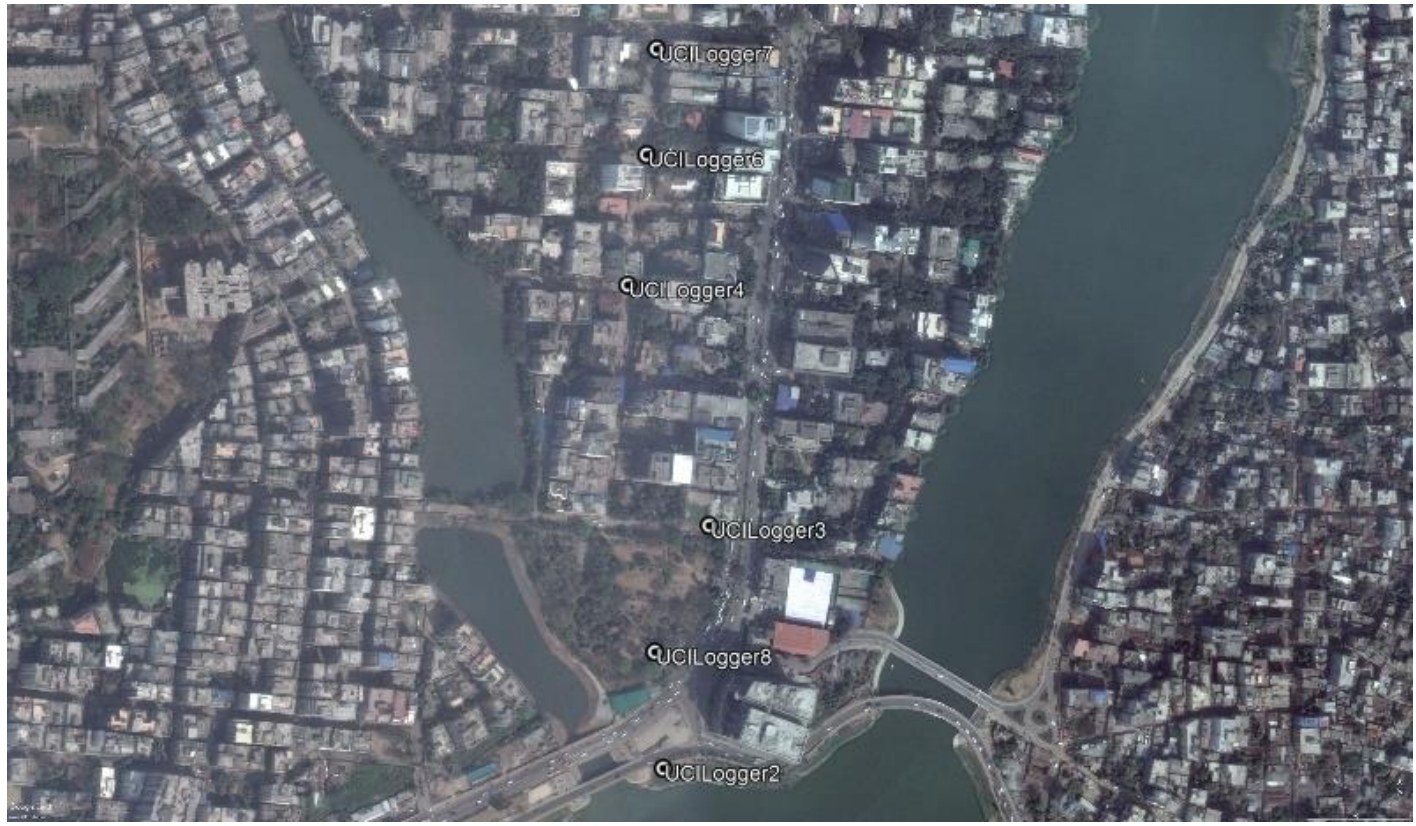

Figure A2. Location of the urban stations of field measurement at Hatirjheel Lake on 10 February 2017.

Table A2. Data logger location at Hatirjheel Lake area, 10 February 2017.

\begin{tabular}{|c|c|c|c|c|c|}
\hline S1 & Logger Name & $\begin{array}{c}\text { Location and Physical } \\
\text { Characteristics of Location }\end{array}$ & Location Photo & $\begin{array}{l}\text { Geographical } \\
\text { Coordinate }\end{array}$ & $\begin{array}{l}\text { Duration of the Data } \\
\text { Logging }\end{array}$ \\
\hline 1 & UCILogger1 & $\begin{array}{l}\text { Mahanagar Bridge (Bridge 2). } \\
\text { Suspended from the middle of the } \\
\text { bridge at } 6 \mathrm{~m} \text { above the top of the } \\
\text { water surface }\end{array}$ & & $\begin{array}{c}\text { Latitude } \\
23.768043 \\
\text { Longitude } \\
90.413047\end{array}$ & $\begin{array}{c}\text { Start } \\
\text { 8:19 a.m. } \\
\text { Finish 5:50 p.m. }\end{array}$ \\
\hline 2 & $\begin{array}{l}\text { UCILogger1-Extech } \\
\text { Dual Sensor }\end{array}$ & $\begin{array}{l}\text { Mahanagar Bridge (Bridge 2). } \\
\text { Suspended from the middle of the } \\
\text { bridge at } 6 \mathrm{~m} \text { above the top of the } \\
\text { water surface }\end{array}$ & & $\begin{array}{c}\text { Latitude } \\
23.768043 \\
\text { Longitude } \\
90.413047\end{array}$ & $\begin{array}{c}\text { Start } \\
\text { 8:25 a.m. } \\
\text { Finish 5:50 p.m. }\end{array}$ \\
\hline 3 & UCILogger2 & $\begin{array}{l}\text { Opposite of Police Plaza Concord. } \\
\text { Cased inside ventilated Particle } \\
\text { board box and tied to the branch of } \\
\text { a shrub, } 1.8 \mathrm{~m} \text { above a } \\
\text { grass-covered ground surface under } \\
\text { the shade of a tree, at the edge of the } \\
\text { water of Hatirjheel Lake. }\end{array}$ & & $\begin{array}{c}\text { Latitude } \\
23.772448 \\
\text { Longitude } \\
90.415489\end{array}$ & $\begin{array}{l}\text { Start } \\
\text { 8:35 a.m. } \\
\text { Finish } \\
\text { 5:50 p.m. }\end{array}$ \\
\hline 4 & $\begin{array}{l}\text { UCILogger2-Extech } \\
\text { Thermo anemometer }\end{array}$ & $\begin{array}{l}\text { Opposite of Police Plaza Concord. } \\
\text { Handheld-1.2 m above a } \\
\text { grass-covered ground surface under } \\
\text { the shade of a tree, at the edge of the } \\
\text { water of Hatirjheel Lake. }\end{array}$ & & $\begin{array}{c}\text { Latitude } \\
23.772448 \\
\text { Longitude } \\
90.415489\end{array}$ & $\begin{array}{l}\text { Start } \\
\text { 8:50 a.m. } \\
\text { Finish } \\
\text { 5:50 p.m. }\end{array}$ \\
\hline 5 & UCILogger3 & $\begin{array}{l}\text { Gulshan } 1 \text { park, opposite of } \\
\text { shooting club. Cased inside a } \\
\text { ventilated particle board box and } \\
\text { tied to the branch of a shrub, } 1.5 \mathrm{~m} \\
\text { above a partly grass-covered } \\
\text { ground surface under the shade of a } \\
\text { tree, } 190 \mathrm{~m} \text { ( } 155 \mathrm{~m} \text { towards east) } \\
\text { away from the edge of the water on } \\
\text { the southern direction }\end{array}$ & & $\begin{array}{c}\text { Latitude } \\
23.774313 \\
\text { Longitude } \\
90.415876\end{array}$ & $\begin{array}{l}\text { Start } \\
\text { 7:50 a.m. } \\
\text { Finish 5:50 p.m. }\end{array}$ \\
\hline
\end{tabular}


Table A2. Cont.

\begin{tabular}{|c|c|c|c|c|c|}
\hline S1 & Logger Name & $\begin{array}{c}\text { Location and Physical } \\
\text { Characteristics of Location }\end{array}$ & Location Photo & $\begin{array}{l}\text { Geographical } \\
\text { Coordinate }\end{array}$ & $\begin{array}{c}\text { Duration of the Data } \\
\text { Logging }\end{array}$ \\
\hline 6 & UCILogger4 & $\begin{array}{l}\text { The junction between road } 2 \text { and } 4 . \\
\text { Cased inside a ventilated particle } \\
\text { board box and tied to the trunk of a } \\
\text { tree, } 1.5 \mathrm{~m} \text { above the paved surface, } \\
\text { approximately } 425 \mathrm{~m} \text { ( } 105 \mathrm{~m} \\
\text { towards NW) away from the edge } \\
\text { of the water in the southern } \\
\text { direction and } 110 \mathrm{~m} \text { from the lake } \\
\text { edge in the western direction. }\end{array}$ & & $\begin{array}{c}\text { Latitude } \\
23.776312 \\
\text { Longitude } \\
90.414983\end{array}$ & $\begin{array}{c}\text { Start } \\
\text { 9:06 a.m. } \\
\text { Finish } \\
\text { 5:50 p.m. }\end{array}$ \\
\hline 7 & UCILogger6 & $\begin{array}{l}\text { The junction between road } 2 \text { and } 6 . \\
\text { Cased inside a ventilated particle } \\
\text { board box and tied to the trunk of } \\
\text { the tree, } 1.5 \mathrm{~m} \text { above the paved } \\
\text { surface, approximately } 550 \mathrm{~m} \\
\text { (164 m towards NW) away from the } \\
\text { edge of the water in the } \\
\text { southern direction }\end{array}$ & & $\begin{array}{c}\text { Latitude } \\
23.777164 \\
\text { Longitude } \\
90.415349\end{array}$ & $\begin{array}{c}\text { Start } \\
\text { 9:17 a.m. } \\
\text { Finish 5:50 p.m. }\end{array}$ \\
\hline 8 & UCILogger7 & $\begin{array}{l}\text { The junction between road } 8 \text { and } 2 \text {. } \\
\text { Cased inside a ventilated particle } \\
\text { board box and tied to the trunk of a } \\
\text { tree, } 1.5 \mathrm{~m} \text { above the paved surface, } \\
\text { approximately } 660 \mathrm{~m} \text { ( } 243 \mathrm{~m} \\
\text { towards } \mathrm{NW} \text { ) away from the edge of } \\
\text { the water in the southern direction }\end{array}$ & & $\begin{array}{c}\text { Latitude } \\
23.777975 \\
\text { Longitude } \\
90.415434\end{array}$ & $\begin{array}{c}\text { Start } \\
\text { 9:25 a.m. } \\
\text { Finish 5:50 p.m. }\end{array}$ \\
\hline 9 & UCILogger8 & $\begin{array}{l}\text { Gulshan-1 park, Police Plaza } \\
\text { complex corner. Cased inside a } \\
\text { ventilated particle board box and } \\
\text { tied to the branch of a shrub, } 1.5 \mathrm{~m} \\
\text { above a partly grass-covered } \\
\text { ground surface under the shade of a } \\
\text { tree, approximately } 120 \mathrm{~m} \text { away } \\
\text { from the edge of the water in the } \\
\text { southern direction }\end{array}$ & & $\begin{array}{c}\text { Latitude } \\
23.773342 \\
\text { Longitude } \\
90.415418\end{array}$ & $\begin{array}{c}\text { Start } \\
\text { 9:45 a.m. } \\
\text { Finish 5:50 p.m. }\end{array}$ \\
\hline 10 & UCILogger8-Davis & $\begin{array}{l}\text { Gulshan- } 1 \text { park, Police Plaza } \\
\text { complex corner. } 2 \text { m above a partly } \\
\text { grass-covered ground surface under } \\
\text { the shade of a tree, approximately } \\
120 \mathrm{~m} \text { away from the edge of the } \\
\text { water in the southern direction }\end{array}$ & & $\begin{array}{c}\text { Latitude } \\
23.773342 \\
\text { Longitude } \\
90.415418\end{array}$ & $\begin{array}{l}\text { Start } \\
\text { 11:30 a.m. } \\
\text { Finish } \\
\text { 5:50 p.m. }\end{array}$ \\
\hline
\end{tabular}

\section{Appendix A.2. Instruments}

The instruments used for data collections are EL-USB-2-LCD Temp and RH Data Logger of Lascar Electronics, Extech 445713: Big Digit Indoor/Outdoor Hygro-Thermometer and Extech AN400 Rotating Cup Thermo-Anemometer. All the measurements were done at a pedestrian level in between a height of 1.5 and $2 \mathrm{~m}$. During the first two measurements in both the study areas, the Lascar instruments were bamboo tripod-mounted in a partly grass-covered ground or paved surface under the shade of a tree. In the second two measurements, Lascar instruments were a ventilated box mounted under the shade 
of a tree. In the case of both the wetlands, all the data logging stations were selected on the downwind side of the wetland except one station on Dhanmondi Lake, which was chosen on the upwind side.

\section{Appendix A.3. Physiography of the Study Area}

The physiography of both the wetlands is the same as they are located on the same physiographic regions and consequent subregions [40]. The physiographic region of the wetland is the Madhupur Tract. Much of the Dhaka city lies on the Madhupur Tract, which could be found in in the map in Brammer, 2012 [40], it has been shown separately. The other important locational information was that both the lakes were located on the same overall geothermal gradient zone [42]. From the above information it could be safely deduced that in terms of heat gain from the ground source both Dhanmondi and Hatirjheel Lakes were in the same category; that means, if they gain heat from the ground, it will be at the same rate. In fact, they will not get any heat at all from the ground source, as the geothermal potential in this location is not high enough. So, it is only the differential shading pattern, due to the big riparian shading and the built form, which will create differential solar gain for both the lakes.

\section{Appendix B}

\section{Appendix B.1. Turbulent Flow}

The flow was modeled using the Wilcox $k-\omega$ turbulence model. The main reason for using the $k-\omega$ model over the $k-\varepsilon$ model is that the former is, in general, more reliable when it comes to predicting the spreading rate of jets [45]. The $k-\omega$ model uses wall functions, which was appropriate in this case since all walls were almost insulated and there would not be much benefit from using the more expensive low-Re $\mathrm{k}-\varepsilon$ model.

Further, it is assumed that the velocity and pressure field was independent of the air temperature and moisture content. This allowed us to calculate the flow field in advance and then used it as input for the heat transfer and species transport equation.

\section{Appendix B.2. Heat Transfer}

The primary source of heat in this model was the solar irradiation, which was included using the external radiation source feature. This feature uses the longitude, latitude, time zone, time of year, and time of day to compute the direction of the incident solar radiation over the simulation time. Assuming no cloud cover, the solar flux at the surface was about $1000 \mathrm{~W} / \mathrm{m}^{2}$. "All of the ambient surfaces of the model were included in the solar loading calculation, and shadowing effects were included. The temperature of the sun is about $5800 \mathrm{~K}$, and it emits primarily short-wavelength infrared and visible light at wavelengths shorter than 2.5 microns" [46]. The fraction of this short-wavelength solar radiation that is absorbed by the various materials was quantified by the solar absorptivity. Since the surfaces are at a much lower temperature, they reradiate in the long-wavelength infrared band, at wavelengths above 2.5 microns, and the fraction of reradiated energy was quantified by the surface emissivity. "The solar and ambient wavelength dependence of emissivity model was used to account for differing emissivities in different wavelength bands" [46].

The heat transfer between the lake and land is due to conduction only. For the air, convection dominates the heat transfer and the turbulent flow field is required. The material properties were determined by the moist air theory. During evaporation, latent heat was released from the water surface, which cools down the water in addition to convective and conductive cooling by the surrounding environment. This means that the fraction of convective and diffusive flux normal to the water surface contributes to the evaporative heat flux [47].

$$
-n \cdot(-\| \nabla T)=H_{\text {vap }} n \cdot(-D \nabla c+u c)
$$


The latent heat of vaporization $H_{\text {vap }}$ is given in $\mathrm{kJ} / \mathrm{mol}$.

\section{Appendix B.3. Transport of Water Vapor}

To obtain the measurement of the correct amount of water evaporated from the lake into the air, the transport of diluted species interface was used in the air domain. The initial concentration was chosen to keep the initial relative humidity (RH) equal to the RH at 9 a.m. in the morning obtained from the field measurement. The source term for water vapor at the water surface is given by the ideal gas law at saturation pressure [48]:

$$
c_{\text {vap }}=\frac{p_{\text {sat }}}{R_{g} T}
$$

The transport equation again uses the turbulent flow field as input. Turbulent was considered for the diffusion coefficient, by adding the following turbulent diffusivity to the diffusion tensor:

$$
D_{T}=\frac{v_{T}}{S c_{T}} I
$$

where $v_{T}$ is the turbulent kinematic viscosity, $S c_{T}$ is the turbulent Schmidt number, and I the unit matrix.

\section{Appendix B.4. Roughness Parameters}

Roughness parameters had been specified for five spatial areas inside the computational domain, as suggested by Blocken (2015) [49]. Area one is upstream of the computational domain. Area two is the area inside the computational domain and upstream of the explicitly modeled building. Area three inside the computational domain represents the ground surface amidst the explicitly modeled buildings and other obstacles. Area four is the surface of the explicitly modeled buildings (façade and roofs) and structures inside the computational domain. Area five is the area inside the computational domain and downstream of the explicitly modeled buildings. Additionally, two types of roughness specification were made [49]:

i. Aerodynamic roughness length $\mathrm{z}_{0}$ : used for area one, two, three, and five;

ii. Equivalent sand-grain roughness length $\mathrm{k}_{\mathrm{s}}$ : used in area four.

For the discretization scheme default second-order elements of "COMSOL" were used.

\section{Appendix C}

\section{Appendix C.1. Reference Measurement at the Bangladesh Meteorological Department}

As stated earlier, one data logger was placed inside the Stevenson screen of the Bangladesh Meteorological department's (BMD) measurement site at Agargaon together with the BMD's instrument. The duration of the measurement was from 11:00 a.m. 12 December 2016 to 11:00 a.m. 14 December 2016. The air temperature and relative humidity data from 6:00 p.m. 12 December to 6:00 a.m. 14 December 2016 of this urban station were analyzed. For the correlational analysis the data was divided into three chunks; first one was 6:00 p.m. 12 December to 6:00 a.m. 13 December 2016 (night); the second one was 6:00 a.m. 13 December to 6:00 p.m. 13 December 2016 (day) and the third one was 6:00 p.m. 13 December to 6:00 a.m. 14 December 2016 (night). Air temperature and relative humidity showed a typical diurnal pattern (Figure A3). At the beginning of the day, air temperature started to rise with a peak between 1:00 p.m. and 3:30 p.m. then started to decline again. Relative humidity shows the opposite trend, with the highest reading at the beginning of the day and continual decline as the day progresses, with the lowest in between 1:00 p.m. and 3:30 p.m. then started to rise again. Air temperature continues to decline after the sunset throughout the night, with the lowest registering between 5:33 a.m. and 7:15 a.m. Again, relative humidity showed the opposite trend, which continued rising after sunset throughout the night with the highest in between 5:34 a.m. and 7:15 a.m. 


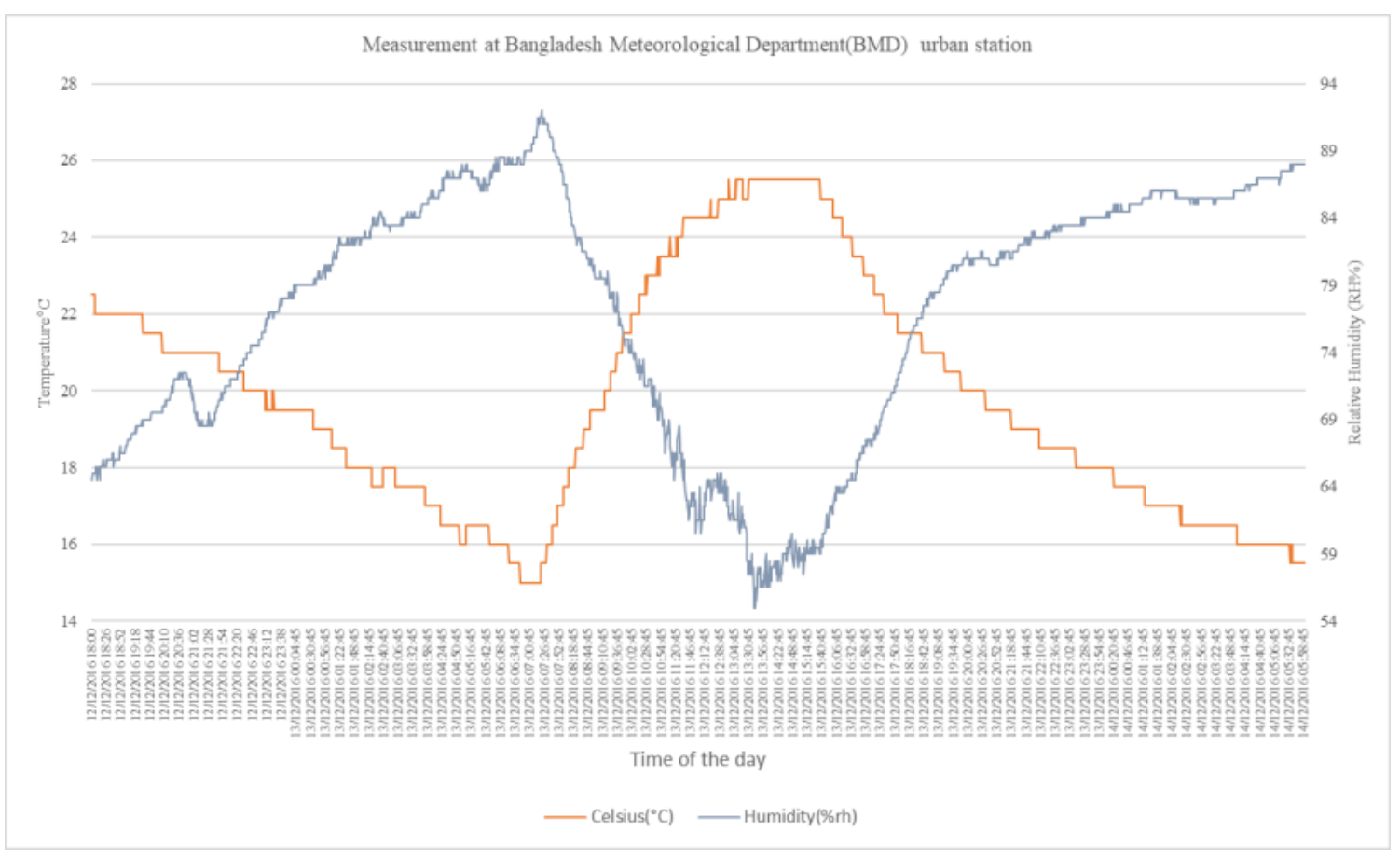

Figure A3. Air temperature and relative humidity measurement at the Bangladesh Meteorological Urban Station (BMD).

The correlation analysis was done separately by dividing the data into the day (6:00 a.m. to 6:00 p.m.) and night (6:00 p.m. to 6:00 a.m.) slots (Table A3). At the beginning of the day, the solar influx started to increase as the sun rose, which continued until afternoon. After that, solar influx started to decrease towards zero at the sunset. The overall rate of change of solar influx throughout the day was positive. At night, with the absence of sun, there was no solar influx and urban rate of heat loss from the urban fabric was constant until the sunrise.

Table A3. Correlation coefficient of air temperature and relative humidity at the Bangladesh Meteorological Department urban station.

\begin{tabular}{cccc}
\hline Variables & $\begin{array}{c}\text { 6:00 p.m. 12 } \\
\text { December to } \\
\text { 6:00 a.m. (Night) }\end{array}$ & $\begin{array}{c}\text { 6:00 a.m. 13 December } \\
\text { to 6:00 p.m. } \\
\text { 13 December 2016 (Day) }\end{array}$ & $\begin{array}{c}\text { 6:00 p.m. 13 December to } \\
\text { 6:00 a.m. }\end{array}$ \\
14 December 2016 (Night)
\end{tabular}

Appendix C.2. Correlation Coefficient between Air Temperature, Relative Humidity and Cumulative Time of the Urban Stations at the Measurement Day

Table A4. Correlation coefficient between air temperature and cumulative time of the urban stations of Dhanmondi Lake on 21 October 2016.

\begin{tabular}{cc}
\hline Urban Stations & Correlation Coefficient \\
\hline UCIL1 $\left({ }^{\circ} \mathrm{C}\right)$ & 0.73 \\
\hline UCIL2 $\left({ }^{\circ} \mathrm{C}\right)$ & 0.39 \\
\hline UCIL4 $\left({ }^{\circ} \mathrm{C}\right)$ & 0.57 \\
\hline UCIL6 $\left({ }^{\circ} \mathrm{C}\right)$ & 0.76 \\
\hline UCIL7 $\left({ }^{\circ} \mathrm{C}\right)$ & 0.06 \\
\hline
\end{tabular}


Table A5. Correlation coefficient between air temperature and cumulative time of the urban stations of Dhanmondi Lake on 27 January 2017.

\begin{tabular}{cc}
\hline Urban Stations & Correlation Coefficient \\
\hline UCIL1 $\left({ }^{\circ} \mathrm{C}\right)$ & 0.36 \\
\hline UCIL2 $\left({ }^{\circ} \mathrm{C}\right)$ & -0.78 \\
\hline UCIL3 $\left({ }^{\circ} \mathrm{C}\right)$ & -0.26 \\
\hline UCIL4 $\left({ }^{\circ} \mathrm{C}\right)$ & 0.45 \\
\hline UCIL5_Hh $\left({ }^{\circ} \mathrm{C}\right)$ & -0.02 \\
\hline UCIL6 $\left({ }^{\circ} \mathrm{C}\right)$ & 0.44 \\
\hline UCIL7 $\left({ }^{\circ} \mathrm{C}\right)$ & 0.37 \\
\hline UCIL8 $\left({ }^{\circ} \mathrm{C}\right)$ & -0.73 \\
\hline UCIL9_Hh $\left({ }^{\circ} \mathrm{C}\right)$ & 0.47
\end{tabular}

Table A6. Correlation coefficient between air temperature and cumulative time of the urban stations of Dhanmondi Lake on 24 February 2017.

\begin{tabular}{ccc}
\hline Urban Stations & Distance from the Water Edge & Correlation Coefficient \\
\hline UCIL1 $\left({ }^{\circ} \mathrm{C}\right)$ & 0 , middle & 0.86 \\
\hline UCIL2 $\left({ }^{\circ} \mathrm{C}\right)$ & 0 , edge & 0.89 \\
\hline UCIL3 $\left({ }^{\circ} \mathrm{C}\right)$ & $80 \mathrm{~m}$ & 0.88 \\
\hline UCIL4 $\left({ }^{\circ} \mathrm{C}\right)$ & $420 \mathrm{~m}$ & 0.87 \\
\hline UCIL6 $\left({ }^{\circ} \mathrm{C}\right)$ & $157 \mathrm{~m}$ & 0.75 \\
\hline UCIL7 $\left({ }^{\circ} \mathrm{C}\right)$ & $230 \mathrm{~m}$ & 0.81 \\
\hline UCIL8 $\left({ }^{\circ} \mathrm{C}\right)$ & $206 \mathrm{~m}$ & 0.70 \\
\hline
\end{tabular}

Table A7. Correlation coefficient between relative humidity and cumulative time of the urban stations of Dhanmondi Lake on 21 October 2016.

\begin{tabular}{cc}
\hline Urban Stations & Correlation Coefficient \\
\hline UCIL1 (\%rh) & -0.58 \\
\hline UCIL2 (\%rh) & -0.33 \\
\hline UCIL4 (\%rh) & -0.58 \\
\hline UCIL6 (\%rh) & -0.64 \\
\hline UCIL7 (\%rh) & -0.09 \\
\hline
\end{tabular}

Table A8. Correlation coefficient between relative humidity and cumulative time of the urban stations of Dhanmondi Lake on 27 January 2017.

\begin{tabular}{cc}
\hline Urban Stations & Correlation Coefficient \\
\hline UCIL1 (\%rh) & 0.06 \\
\hline UCIL2 (\%rh) & 0.78 \\
\hline UCIL3 (\%rh) & 0.28 \\
\hline UCIL4 (\%rh) & -0.17 \\
\hline UCIL6 (\%rh) & -0.25 \\
\hline UCIL7 (\%rh) & 0.12 \\
\hline UCIL8 (\%rh) & 0.63 \\
\hline
\end{tabular}


Table A9. Correlation coefficient between relative humidity and cumulative time of the urban stations of Dhanmondi Lake on 24 February 2017.

\begin{tabular}{ccc}
\hline Urban Stations & Distance from the Water Edge & Correlation Coefficient \\
\hline UCIL1 $\%$ rh) & 0, middle & -0.71 \\
\hline UCIL2 $(\% \mathrm{rh})$ & 0 , edge & -0.59 \\
\hline UCIL3 $\%$ rh) & $80 \mathrm{~m}$ & -0.52 \\
\hline UCIL4 $(\% \mathrm{rh})$ & $420 \mathrm{~m}$ & -0.79 \\
\hline UCIL6 $(\% \mathrm{rh})$ & $157 \mathrm{~m}$ & -0.23 \\
\hline UCIL7 $(\% \mathrm{rh})$ & $230 \mathrm{~m}$ & -0.66 \\
\hline UCIL8 $\% \mathrm{rh})$ & $206 \mathrm{~m}$ & -0.43 \\
\hline
\end{tabular}

Table A10. Correlation coefficient between air temperature and cumulative time of the urban stations of Hatirjheel Lake on 11 November 2016.

\begin{tabular}{ccc}
\hline Urban Statins & Distance from the Water Edge & Correlation Coefficient \\
\hline UCIL1 $\left({ }^{\circ} \mathrm{C}\right)$ & $0 \mathrm{~m}$, middle & 0.56 \\
\hline UCIL2 $\left({ }^{\circ} \mathrm{C}\right)$ & $190 \mathrm{~m}$, park & 0.55 \\
\hline UCIL6 $\left({ }^{\circ} \mathrm{C}\right)$ & $0 \mathrm{~m}$, edge & 0.53 \\
\hline UCIL7 $\left({ }^{\circ} \mathrm{C}\right)$ & $100 \mathrm{~m}$ & 0.39 \\
\hline UCIL8 $\left({ }^{\circ} \mathrm{C}\right)$ & $425 \mathrm{~m}$ & -0.04 \\
\hline
\end{tabular}

Table A11. Correlation coefficient between air temperature and cumulative time of the urban stations of Hatirjheel Lake on 13 December 2016.

\begin{tabular}{cc}
\hline Urban Stations & Correlation Coefficient \\
\hline UCIL1 $\left({ }^{\circ} \mathrm{C}\right)$ & 0.65 \\
\hline $\mathrm{UCIL} 2\left({ }^{\circ} \mathrm{C}\right)$ & 0.80 \\
\hline $\mathrm{UCIL} 6\left({ }^{\circ} \mathrm{C}\right)$ & 0.92 \\
\hline $\operatorname{UCIL7}\left({ }^{\circ} \mathrm{C}\right)$ & 0.91 \\
\hline $\operatorname{UCIL} 8\left({ }^{\circ} \mathrm{C}\right)$ & 0.79 \\
\hline
\end{tabular}

Table A12. Correlation coefficient between air temperature and cumulative time of the urban stations of Hatirjheel Lake on 10 February 2017.

\begin{tabular}{ccc}
\hline Urban Stations & Distance from the Water Edge & Correlation Coefficient \\
\hline UCIL1 $\left({ }^{\circ} \mathrm{C}\right)$ & $0 \mathrm{~m}$ & 0.92 \\
\hline $\mathrm{UCIL} 2\left({ }^{\circ} \mathrm{C}\right)$ & $0 \mathrm{~m}$ water Edge & 0.88 \\
\hline $\mathrm{UCIL} 8\left({ }^{\circ} \mathrm{C}\right)$ & $120 \mathrm{~m}$, middle of the park & 0.77 \\
\hline $\mathrm{UCIL} 3\left({ }^{\circ} \mathrm{C}\right)$ & $190 \mathrm{~m}$, edge of the park & 0.82 \\
\hline $\mathrm{UCIL} 4\left({ }^{\circ} \mathrm{C}\right)$ & $425 \mathrm{~m}$ & 0.58 \\
\hline $\operatorname{UCIL6}\left({ }^{\circ} \mathrm{C}\right)$ & $550 \mathrm{~m}$ & 0.59 \\
\hline $\operatorname{UCIL7}\left({ }^{\circ} \mathrm{C}\right)$ & $660 \mathrm{~m}$ & 0.68 \\
\hline
\end{tabular}


Table A13. Correlation coefficient between relative humidity and cumulative time of the urban stations of Hatirjheel Lake on 11 November 2016.

\begin{tabular}{cc}
\hline Urban Stations & Correlation Coefficient \\
\hline UCIL1 $(\% \mathrm{rh})$ & -0.49 \\
\hline UCIL2 (\%rh) & -0.52 \\
\hline UCIL6 (\%rh) & -0.46 \\
\hline UCIL7 (\%rh) & -0.40 \\
\hline UCIL8 (\%rh) & -0.11 \\
\hline
\end{tabular}

Table A14. Correlation coefficient between relative humidity and cumulative time of the urban stations of Hatirjheel Lake on 13 December 2016.

\begin{tabular}{cc}
\hline Urban Stations & Correlation Coefficient \\
\hline UCIL1 (\%rh) & -0.59 \\
\hline UCIL2 (\%rh) & -0.84 \\
\hline UCIL6 (\%rh) & -0.86 \\
\hline UCIL7 (\%rh) & -0.85 \\
\hline UCIL8 (\%rh) & -0.82 \\
\hline
\end{tabular}

Table A15. Correlation coefficient between relative humidity and cumulative time of the urban stations of Hatirjheel Lake on 10 February 2017.

\begin{tabular}{ccc}
\hline Urban Stations & Distance from the Water Edge & Correlation Coefficient \\
\hline UCIL1 $(\% \mathrm{rh})$ & $0 \mathrm{~m}$ & -0.90 \\
\hline UCIL2 $(\% \mathrm{rh})$ & $0 \mathrm{~m}$ water Edge & -0.90 \\
\hline UCIL8 $(\% \mathrm{rh})$ & $120 \mathrm{~m}$, middle of the park & -0.83 \\
\hline UCIL3 $(\% \mathrm{rh})$ & $190 \mathrm{~m}$, edge of the park & -0.89 \\
\hline UCIL4 $(\% \mathrm{rh})$ & $425 \mathrm{~m}$ & -0.78 \\
\hline UCIL6 $\% \mathrm{rh})$ & $550 \mathrm{~m}$ & -0.74 \\
\hline UCIL7 $(\% \mathrm{rh})$ & $660 \mathrm{~m}$ & -0.79 \\
\hline
\end{tabular}

Appendix C.3. Correlation Coefficient between Simulated Air Temperature, Relative Humidity, and Cumulative Time of the Urban Stations at the Measurement Day

Table A16. Case 1—correlation analysis of air temperature, relative humidity and time.

\begin{tabular}{ccc}
\hline $\begin{array}{c}\text { Measurement } \\
\text { Point }\end{array}$ & $\begin{array}{c}\text { Pearson's Product-Moment } \\
\text { Correlation Coefficient for Air } \\
\text { Temperature }\end{array}$ & $\begin{array}{c}\text { Pearson's Product-Moment } \\
\text { Correlation Coefficient for } \\
\text { Relative Humidity }\end{array}$ \\
\hline UCIL2 & 0.90 & 0.89 \\
\hline UCIL3 & 0.91 & 0.52 \\
\hline UCIL4 & 0.92 & -0.84 \\
\hline UCIL5 & 0.92 & 0.61 \\
\hline UCIL6 & 0.85 & 0.13 \\
\hline UCIL7 & 0.92 & -0.85 \\
\hline UCIL8 & 0.82 & -0.06 \\
\hline
\end{tabular}


Table A17. Case 2-correlation analysis of air temperature, relative humidity, and time.

\begin{tabular}{ccc}
\hline $\begin{array}{c}\text { Measurement } \\
\text { Point }\end{array}$ & $\begin{array}{c}\text { Pearson's Product-Moment } \\
\text { Correlation Coefficient for Air } \\
\text { Temperature }\end{array}$ & $\begin{array}{c}\text { Pearson's Product-Moment } \\
\text { Correlation Coefficient for } \\
\text { Relative Humidity }\end{array}$ \\
\hline UCIL2 & 0.98 & 0.73 \\
\hline UCIL3 & 0.94 & 0.47 \\
\hline UCIL4 & 0.94 & -0.84 \\
\hline UCIL5 & 0.95 & 0.53 \\
\hline UCIL6 & 0.87 & 0.15 \\
\hline UCIL7 & 0.93 & -0.85 \\
\hline UCIL8 & 0.84 & -0.05 \\
\hline
\end{tabular}

Table A18. Case 3-correlation analysis of air temperature, relative humidity, and time.

\begin{tabular}{ccc}
\hline $\begin{array}{c}\text { Measurement } \\
\text { Point }\end{array}$ & $\begin{array}{c}\text { Pearson's Product-Moment } \\
\text { Correlation Coefficient for Air } \\
\text { Temperature }\end{array}$ & $\begin{array}{c}\text { Pearson's Product-Moment } \\
\text { Correlation Coefficient for } \\
\text { Relative Humidity }\end{array}$ \\
\hline UCIL2 & 0.82 & 0.35 \\
\hline UCIL3 & 0.84 & -0.38 \\
\hline UCIL4 & 0.91 & -0.89 \\
\hline UCIL5 & 0.84 & -0.37 \\
\hline UCIL6 & 0.78 & -0.55 \\
\hline UCIL7 & 0.91 & -0.89 \\
\hline UCIL8 & 0.73 & -0.52 \\
\hline
\end{tabular}

Table A19. Case 4-correlation analysis of air temperature, relative humidity, and time.

\begin{tabular}{ccc}
\hline $\begin{array}{c}\text { Measurement } \\
\text { Point }\end{array}$ & $\begin{array}{c}\text { Pearson's Product-Moment } \\
\text { Correlation Coefficient for Air } \\
\text { Temperature }\end{array}$ & $\begin{array}{c}\text { Pearson's Product-Moment } \\
\text { Correlation Coefficient for } \\
\text { Relative Humidity }\end{array}$ \\
\hline UCIL2 & 0.97 & 0.14 \\
\hline UCIL3 & 0.90 & -0.37 \\
\hline UCIL4 & 0.93 & -0.89 \\
\hline UCIL5 & 0.91 & -0.36 \\
\hline UCIL6 & 0.81 & -0.53 \\
\hline UCIL7 & 0.93 & -0.89 \\
\hline UCIL8 & 0.76 & -0.50 \\
\hline
\end{tabular}

Table A20. Correlation between inversion height and fetch.

\begin{tabular}{cc}
\hline & $\begin{array}{c}\text { Pearson's Product-Moment Correlation } \\
\text { between Inversion Height } \mathbf{z} \text { and Fetch } \mathbf{x}\end{array}$ \\
\hline Case 1 & 0.85 \\
\hline Case 2 & 0.80 \\
\hline Case 3 & -0.38 \\
\hline Case 4 & -0.59 \\
\hline
\end{tabular}




\section{Appendix D}

Urban Design Matrix

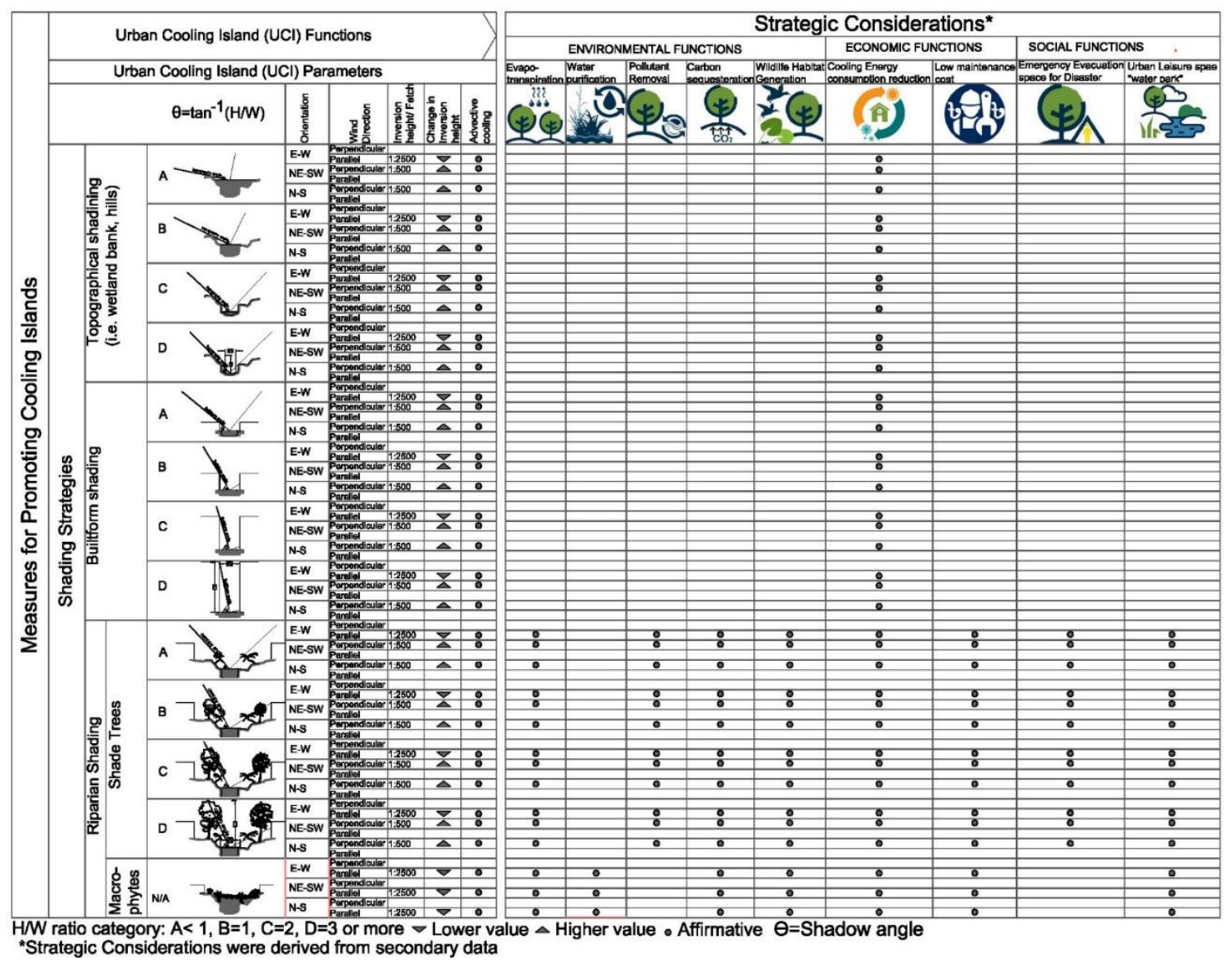

Figure A4. Urban design matrix for the urban wetland.

\section{References}

1. IPCC. Climate Change 2014: Synthesis Report. Contribution of Working Groups I, II, and III to the Fifth Assessment Report of the Intergovernmental Panel on Climate Change; Core Writing Team, Pachauri, R.K., Meyer, L.A., Eds.; IPCC: Geneva, Switzerland, 2014; 151p.

2. Ahmed, R. In search of the impact of urbanization on the thermal environment of the city of Dhaka, Bangladesh, during the pre-monsoon hot season from 1948 through 1987. In Proceedings of the Report of the Technical Conference on Tropical Urban Climates, Dhaka, Bangladesh, 28 March-2 April 1993; World Meteorological Organization (WMO): Geneva, Switzerland, 1993.

3. Bangladesh Bureau of Statistics; Statistics and Informatics Division; Ministry of Planning. Population and Housing Census 2011, Statistics and Informatics Division, Ministry of Planning; Community Report; Bangladesh Bureau of Statistics: Dhaka Zila, Bangladesh, 2012. Available online: http://bbs.dhaka.gov.bd/sites/default/files/files/bbs.dhaka.gov.bd/law_policy/6ed6b42c_2015_11e7_8f57_ 286ed488c766/Socio-Economic\%20and\%20demographic\%20Report\%202012.pdf (accessed on 29 March 2016).

4. Ahmed, B.; Kamruzzaman, M.; Zhu, X.; Rahman, S.M.; Choi, K. Simulating Land Cover Changes and Their Impacts on Land Surface Temperature in Dhaka, Bangladesh. Remote Sens. 2013, 5, 5969-5998. [CrossRef]

5. Sun, R.; Chen, L. How can urban water bodies be designed for climate adaptation? Landsc. Urban. Plan. 2012, 105, 27-33. [CrossRef]

6. Steeneveld, G.J.; Koopmans, S.; Heusinkveld, B.G.; Theeuwes, N.E. Refreshing the role of open water surfaces on mitigating the maximum urban heat island effect. Landsc. Urban. Plan. 2014, 121, 92-96. [CrossRef] 
7. Taleghani, M.; Tenpierik, M.; Dobbelsteen, A.V.D.; Sailor, D.J. Heat in courtyards: A validated and calibrated parametric study of heat mitigation strategies for urban courtyards in the Netherlands. Sol. Energy 2014, 103, 108-124. [CrossRef]

8. Saaroni, H.; Ziv, B. The impact of a small lake on heat stress in a Mediterranean urban park: The case of Tel Aviv, Israel. Int. J. Biometeorol. 2003, 47, 156-165. [CrossRef]

9. Cheng, L.; Guan, D.; Zhou, L.; Zhao, Z.; Zhou, J. Urban cooling island effect of main river on a landscape scale in Chongqing, China. Sustain. Cities Soc. 2019, 47, 101501. [CrossRef]

10. Frey, C.M.; Rigo, G.; Parlow, E. Investigation of the Daily Urban. Cooling Island (UCI) in Two Coastal Cities in an Arid Environment: Dubai and Abu Dhabi (UAE); Institute of Meteorology, Climatology and Remote Sensing, Department of Geosciences, University of Basel: Basel, Switzerland, 2009.

11. Gupta, N.; Mathew, A.; Khandelwal, S. Analysis of cooling effect of water bodies on land surface temperature in nearby region: A case study of Ahmedabad and Chandigarh cities in India. Egypt. J. Remote Sens. Space Sci. 2019, 22, 81-93. [CrossRef]

12. Han, G.; Chen, H.; Yuan, L.; Cai, Y.; Han, M. Field measurements on micro-climate and cooling effect of river wind on urban blocks in Wuhan city. In Proceedings of the International Conference on Multimedia Technology (ICMT), Hangzhou, China, 26-28 July 2011. [CrossRef]

13. Kim, Y.H.; Ryoo, S.B.; Baik, J.J.; Park, I.S.; Koo, H.J.; Nam, J.C. Does the restoration of an inner-city stream in Seoul affect local thermal environment? Theor. Appl. Climatol. 2008, 92, 239-248. [CrossRef]

14. Manteghi, G.; Lamit, H.B.; Ossen, D.R. Influence of Street Orientation and Distance to Water Body on Microclimate Temperature Distribution in Tropical Coastal City of Malacca. Int. J. Appl. Environ. Sci. 2015, 10, 749-766.

15. Mitchell, V.G.; Cleugh, H.A.; Grimmond, C.S.B.; Xu, J. Linking urban water balance and energy balance models to analyze urban design options. Hydrol. Process. 2008, 22, 2891-2900. [CrossRef]

16. Nishimura, N.; Nomura, T.; Iyota, H.; Kimoto, S. Novel water facilities for creation of comfortable urban micrometeorology. Sol. Energy 1998, 64, 197-207. [CrossRef]

17. Park, C.Y.; Lee, D.K.; Asawa, T.; Murakami, A.; Kim, H.G.; Lee, M.K.; Lee, H.S. Influence of urban form on the cooling effect of a small urban river. Landsc. Urban. Plan. 2019, 183, 26-35. [CrossRef]

18. Robitu, M.; Musy, M.; Inard, C.; Groleau, D. Modeling the influence of vegetation and water pond on urban microclimate. Sol. Energy 2006, 80, 435-447. [CrossRef]

19. Rutherford, J.C.; Blackett, S.; Blackett, C.; Saito, L.; Colley, R.J.D. Predicting the effects of shade on water temperature in small streams. N. Z. J. Mar. Freshw. Res. 1997, 31, 707-721. [CrossRef]

20. Rutherford, J.C.; Marsh, N.A.; Davies, P.M.; Bunn, S.E. Effect of patchy shade on stream water temperature: How quickly do small streams heat and cool. Mar. Freshw. Res. 2004, 55, 737-748. [CrossRef]

21. Sun, R.; Chen, A.; Chen, L.; Lü, Y. Cooling effects of wetlands in an urban region: The case of Beijing. Ecol. Indic. 2012, 20, 57-64. [CrossRef]

22. Theeuwes, N.E.; Solcerová, A.; Steeneveld, G.J. Modeling the influence of open water surfaces on the summertime temperature and thermal comfort in the city. J. Geophys. Res. Atmos. 2013, 118, 8881-8896. [CrossRef]

23. Tominaga, Y.; Sato, Y.; Sadohara, S. CFD simulations of the effect of evaporative cooling from water bodies in a micro-scale urban environment: Validation and application studies. Sustain. Cities Soc. 2015, 19, 259-270. [CrossRef]

24. Xiyan, X.; Shuming, L.; Shibo, S.; Wenwei, Z.; Ying, L.; Zhaoming, L.; Guancheng, G.; Smith, K.; Yong, C.; Wei, L.; et al. Evaluation of energy saving potential of an urban green space and its water bodies. Energy Build. 2019, 188-189, 58-70.

25. Fraedrich, K. On the evaporation of a lake in warm and dry environment. Tellus 1972, 24, 116-121. [CrossRef]

26. Bowler, D.E.; Mant, R.; Orr, H.; Hannah, D.M.; Pullin, A.S. What are the effects of wooded riparian zones on stream temperature? Environ. Evid. 2012, 1, 3. [CrossRef]

27. Johnson, M.F.; Wilby, R.L. Seeing the landscape for the trees: Metrics to guide riparian shade management in river catchments. Water Resour. Res. 2015, 51, 3754-3769. [CrossRef]

28. Larson, L.L.; Larson, S.L. Riparian Shade and Stream Temperature: A Perspective. Rangelands 1996, 18, 149-152.

29. Somers, K.A.; Bernhardt, E.S.; Grace, J.B.; Hassett, B.A.; Sudduth, E.B.; Wang, S.; Urban, D.L. Streams in the urban heat island: Spatial and temporal variability in temperature. Freshw. Sci. 2013, 32, 309-326. [CrossRef] 
30. Sweeney, B.W.; Newbold, J.D. Streamside forest buffer width needed to protect stream water quality, habitat, and organisms: A literature review. J. Am. Water Resour. Assoc. 2014, 50, 560-584. [CrossRef]

31. Rosenb, N.J.; Blad, B.L.; Verma, S.B. Microclimate-The Biological Environment; John Wiley and Sons: New York, NY, USA, 1983.

32. Dyer, A.J.; Crawford, T.V. Observations of the microclimate at a leading-edge. Q. J. R. Meteorol. Soc. 1965, 91, 345-348. [CrossRef]

33. Goltz, S.M.; Pruitt, W.O. Spatial and Temporal Variations of Evapotranspiration Downwind from the Leading Edge of a Dry Fallow Field; Div. Technical Report ECOM68-G10-1; Department of Water Science and Engineering, University of California at Davis: Davis, CA, USA, 1970.

34. Lang, A.R.G.; Evans, G.N.; Ho, P.Y. The influence of local advection on evapotranspiration from irrigated rice in a semi-arid region. Agric. Meteorol. 1974, 13, 5-13. [CrossRef]

35. Rider, N.E.; Philip, J.R.; Bradley, E.F. The horizontal transport of heat and moisture-a micrometeorological study. Q. J. R. Meteorol. Soc. 1963, 89, 507-531. [CrossRef]

36. Rijks, D.A. Water use by irrigated cotton in Sudan: III. Bowen ratios and advective energy. J. Appl. Ecol. 1971, 8, 643-663. [CrossRef]

37. Oke, T.R. Advectively-assisted evapotranspiration from irrigated urban vegetation. Bound. Layer Meteorol. 1979, 17, 167-173. [CrossRef]

38. Ahmed, K.S. Approaches to Bioclimatic Urban Design for the tropics with special reference to Dhaka, Bangladesh. Ph.D. Thesis, Environment and Energy Studies Programme, Architectural Association School of Architecture, London, UK, 1995.

39. Shahjahan, A.T.M.; Ahmed, K.S. Study of urban water bodies in view of potential for micro-climatic cooling and natural purification of waste water. In Balanced Urban Development: Options and Strategies for Liveable Cities; Basant, M., Vijay, P.S., Bhadranie, T., Eds.; Springer International Publishing: Cham, Germany, 2016.

40. Brammer, H. The Physical Geography of Bangladesh, 1st ed.; The University Press Limited: Dhaka, Bangladesh, 2012.

41. FAO/UNDP. Land Resources Appraisal of Bangladesh for Agricultural Development Report 2: Agro-Ecological Regions of Bangladesh; FAO: Rome, Italy, 1988; Rep. No. 2.

42. Akbar, M.A. An Assessment of the Geothermal Potential of Bangladesh; United Nations University: Reykjavik, Iceland, 2011; pp. 1-33, Rep. No. 5.

43. Oke, T.R. Initial Guidance to Obtain Representative Meteorological Observations at Urban Site. In World Meteorological Organization, Instruments, and Observing Methods; WMO: Geneva, Switzerland, 2006; IOM Report No. 81, WMO/TD-No. 1250.

44. Huang, L.; Li, J.; Zhao, D.; Zhu, J. A fieldwork study on the diurnal changes of urban microclimate in four types of ground cover and urban heat island of Nanjing, China. Build. Environ. 2008, 43, 7-17. [CrossRef]

45. Wilcox, D.C. Turbulence Modeling for CFD; DCW industries Inc.: La Canada, CA, USA, 1998.

46. COMSOL Documentation. Available online: https://www.comsol.com/documentation (accessed on 1 February 2018).

47. Incropera, F.P.; DeWitt, D.P.; Bergman, T.L.; Lavine, A.S. Fundamentals of Heat and Mass Transfer, 6th ed.; John Wiley \& Sons: Hoboken, NJ, USA, 2006.

48. Monteith, J.L.; Unsworth, M.H. Principles of Environmental Physics, 4th ed.; Academic Press: Cambridge, MA, USA, 2013.

49. Blocken, B. Computational Fluid Dynamics for urban physics: Importance, scales, possibilities, limitations and ten tips and tricks towards accurate and reliable simulations. Build. Environ. 2015, 91, 219-245. [CrossRef]

Publisher's Note: MDPI stays neutral with regard to jurisdictional claims in published maps and institutional affiliations. 